\title{
Learning About a Shift in Trend Output: Implications for Monetary Policy and Inflation*
}

\author{
Kevin J. Lansing ${ }^{\dagger}$ \\ Federal Reserve Bank of San Francisco
}

July 1, 2002

\begin{abstract}
This paper develops a small forward-looking macroeconomic model where the Federal Reserve estimates the level of potential output in real time by running a regression on past output data. The Fed's perceived output gap is used as an input to the monetary policy rule while the true output gap influences aggregate demand and inflation. I investigate the consequences of two abrupt shifts in the growth rate of true potential output: the first occurs in the early$1970 \mathrm{~s}$ and the second in the mid-1990s. Initially, Fed policymakers interpret these shifts to be cyclical shocks but their regression algorithm allows them to gradually discover the truth as the economy evolves over time. Using stochastic simulations, I show that the model can replicate some of the low-frequency movements in U.S. inflation over the past several decades. Under a Taylor-type rule, the model produces a hump-shaped pattern in trend inflation that peaks around 1979 and a downward movement in trend inflation after 1995. Under a nominal income growth rule, these low-frequency movements are reduced but not eliminated. The business cycle stabilization properties of the two policy rules turn out to be broadly similar.
\end{abstract}

Keywords: Monetary Policy, Inflation, Business Cycles, Learning.

JEL Classification: E31, E32, E43, E52.

\footnotetext{
* For helpful comments and suggestions, I thank John Carlson, James Bullard, John Leahy, Glenn Rudebusch, and participants in the FRBSF/SIEPR Conference on Structural Change and Monetary Policy, San Francisco, March 2000 and the NBER Summer Institute, Cambridge, July 2000. The views in this paper are my own and not necessarily those of the Federal Reserve Bank of San Francisco or of the Federal Reserve System.

$\dagger$ Research Department, Federal Reserve Bank of San Francisco, P.O. Box 7702, San Francisco, CA 94120-7702, (415) 974-2393, FAX: (415) 977-4031, email: kevin.j.lansing@sf.frb.org, homepage: www.frbsf.org/economics/economists/klansing.html
} 


\section{Introduction}

What accounts for the rise of U.S. inflation during the 1960s and 1970s (often referred to as the "Great Inflation") and the subsequent fall in the early 1980s? A satisfactory theory of the historical pattern should address the following questions:

- Why did events happen when they did? In other words, what was different about the period from 1965 to 1980 that allowed CPI inflation to go from less than 2 percent to over 12 percent? Why did the disinflation occur in the early 1980s and not some other period?

- Why do we see a similar historical pattern for inflation in Canada and many European and Pacific Basin countries? ${ }^{1}$

- Can these events happen again?

Theories about the Great Inflation fall roughly into one of three categories: bad luck theories (which emphasize chance events outside the Fed's control), policy mistake theor ies (which emphasize discretionary actions by Fed policymakers), or combination theories (where chance and discretion both play a role). ${ }^{2}$

This paper develops a small macroeconomic model to investigate the plausibility of a specific bad-luck theory of the Great Inflation advanced recently by Orphanides (1999). The hypothesis is that Fed policymakers did not know, until some years later, that the economy's sustainable growth path had undergone an abrupt downward shift in level and slope in the early 1970s (see Figure 1). The story explored here goes like this: Fed policymakers of the 1970s were in fact using a version of the Taylor (1993) policy rule that appears to capture Fed behavior during the low inflation era of the late 1980s and 1990s. A crucial input to the rule is the gap between observed output and "potential" output. To construct a measure of potential output, Fed policymakers fit a trend through the historical data. When the incoming data started falling below trend because of the unobserved structural break, Fed policymakers interpreted the data as evidence of a recession. Following the advice of their policy rule, they lowered short-term interest rates in response to the perceived negative output gap. Lower interest rates stimulated aggregate demand. Stronger demand, combined with the abrupt reduction in the economy's productive capacity, caused the true output gap to become positive. This, in turn, led to higher inflation. As more data was received, the Fed adjusted its trend, shrinking the size of the perceived negative output gap. However, with interest rates still below previous levels and the true gap still positive, inflation continued to rise. Eventually, the policy rule called for the Fed to reverse course and start raising interest rates to fight inflation. The momentum in inflation was such that the Fed was not able to turn things around until the early 1980 s.

In simulations with a Taylor-type rule, I find that the model can replicate some of the key low-

\footnotetext{
${ }^{1}$ For the evidence, see Parkin (1993), Bomhoff (1993), and Fry (1993).

${ }^{2}$ See Lansing (2000) for a brief summary of the various theories.
} 
frequency movements in U.S. inflation over the past several decades. I focus on the low-frequency movements in the data because these are more likely to be dominated by a permanent shock to economy's sustainable growth path. Moreover, this metholology allows room for short-term factors, such as oil and food price shocks, to have played a role in generating the actual time series of U.S. inflation. The model can produce a hump-shaped pattern in trend inflation that peaks around 1979:2. It can also match the low-frequency lead-lag behavior of the U.S. variables whereby the output gap peaks before 1979:2 and the federal funds rate peaks after 1979:2 (see Figure 2).

In light of these results, it is worthwhile to go back and consider the questions listed above. According to this theory, the productivity slowdown was the key event that made inflation start to rise. ${ }^{3}$ This aspect of the theory may help to explain the similar inflation patterns of other countries because many developed economies experienced productivity slowdowns around the same time. ${ }^{4}$

Research on the dating of the productivity slowdown generally places it sometime in early 1970s. As such, the theory cannot explain why U.S. inflation began rising in the mid-1960s. It is possible to argue, of course, that Fed policymakers believed that the U.S. economy was operating below potential in the mid-1960s and that this perception motivated their pursuit of overly-expansionary monetary policy starting then. While this may be true, such a phenomenon cannot be captured by the model because the mechanism for rising inflation requires the occurrence of an actual trend shift in the underlying economy.

The theory provides a rationale for the timing of the disinflation, as the combination of the Fed's sluggish learning of the productivity slowdown and the inherent momentum in inflation could explain why it took until 1979:2 before trend inflation peaked and started heading back down. It turns out that the model can account for less than one-half of the decline in trend inflation after 1979:2. One could argue that this makes sense, however, because the model abstracts from any changes in the Fed's policy rule. The policy rule may have changed with the appointment of Fed Chairman Volcker in August 1979.

Finally, the theory suggests that the above events, or their mirror image, can happen again. In second-half of the 1990s, for example, the U.S. economy experienced a surge in capital investment linked to computers and information technology. ${ }^{5}$ Measured productivity growth picked up while inflation remained low despite a steady decline in the unemployment rate. Such observations have led some policymakers and economists to conclude that another structural break in the economy's

\footnotetext{
${ }^{3}$ That the slowdown happened is not much in dispute. Why it happened is another matter. Numerous theories exist but none are completely satisfactory. These include: (1) a return to "normal" productivity growth from the unsustainably high growth rates experienced after the Great Depression and World War II, (2) adverse trends in fiscal policy, i.e., rising tax rates and falling infrastructure spending, (3) demographic shifts that have reduced the quality of the labor force, (4) a fall-off in the rate of research and development spending, (5) increased costs of complying with government regulations, (6) increases in energy costs due to oil price shocks, (7) difficulties in measuring service-sector productivity, and (8) temporary inefficiencies linked to the adoption of new technologies.

${ }^{4}$ See Nelson and Nikolov (2001) for a study of how real-time gap measurement errors may help to account for inflation patterns in the U.K.

${ }^{5}$ For some evidence, see Oliner and Sichel (2000).
} 
sustainable growth path has occurred, this time in the positive direction. This is the celebrated "new economy" view. ${ }^{6}$ Under this interpretation of the theory, incoming data continues to plot above the Fed's estimated trend because of the unobserved structural break. Fed policymakers view the data as evidence of a boom. Following the advice of their policy rule, they raise short-term interest rates in an effort to restrain aggregate demand. This action, combined with the expansion of the economy's productive capacity, pushes the true output gap into negative territory. The sustained negative output gap leads to a decline in trend inflation after 1995:4. A similar pattern also appears in U.S. data.

The use of a nominal income growth rule in the simulations serves to reduce the low-frequency movements in model inflation. Under such a rule, Fed policymakers respond to the change in the perceived output gap rather to the level of the perceived output gap. This setup allows the real-time gap measurement errors (which are strongly autocorrelated) to offset one another. In comparing the business cycle stabilization properties of the nominal income growth rule to those of the Taylortype rule, I find that the results are broadly similar. The nominal income growth rule yields slightly higher standard deviations for the output gap and the nominal interest rate, but lower standard deviations for inflation and nominal income growth.

The remainder of the paper is organized as follows. Section 2 describes the model. Section 3 presents maximum likelihood parameter estimates. Section 4 presents the results of the quantitative simulations. Section 5 concludes. Appendix A provides details on the derivation of the nominal income growth rule.

\section{The Model}

I use a simplified version of the forward-looking model developed by Fuhrer and Moore (1995). The timing of agents' expectations is structured to permit a closed-form solution. This is helpful for identifying the parameters that are important for determining the quantitative impact of the Fed's real-time measurement errors on inflation and other variables. The equations that describe the model are as follows:

$$
\begin{aligned}
& y_{t}-\bar{y}_{t}= a_{1}\left(y_{t-1}-\bar{y}_{t-1}\right)+a_{2}\left(y_{t-2}-\bar{y}_{t-2}\right)+a_{\rho}\left(\rho_{t-1}-\bar{\rho}\right)+v_{t}, \quad v_{t} \sim N\left(0, \sigma_{v}^{2}\right), \\
& \bar{y}_{t}=\left\{\begin{array}{cl}
c_{0}+\mu_{0} \cdot t & \text { for } t_{0} \leq t \leq t_{1}, \\
c_{1}+\mu_{1} \cdot t & \text { for } t_{1}<t \leq t_{2}, \\
c_{2}+\mu_{2} \cdot t & \text { for } t>t_{2},
\end{array}\right. \\
& \pi_{t}=\frac{1}{2}\left(\pi_{t-1}+E_{t-1} \pi_{t}\right)+\gamma\left(y_{t-1}-\bar{y}_{t-1}\right)+z_{t}, \quad z_{t} \sim N\left(0, \sigma_{z}^{2}\right)
\end{aligned}
$$

\footnotetext{
${ }^{6}$ Gordon (2000) argues that a proper analysis of the productivity data does not support the new economy view.
} 


$$
\begin{aligned}
\rho_{t-1} & =\frac{1}{2} E_{t-1} \sum_{i=0}^{1}\left(r_{t-1+i}-\pi_{t+i}\right)=\frac{1}{2}\left(r_{t-1}-E_{t-1} \pi_{t}+E_{t-1} r_{t}-E_{t-1} \pi_{t+1}\right) \\
r_{t} & =\left(1-\alpha_{r}\right)(\bar{\rho}+\bar{\pi})+\alpha_{r} r_{t-1}+\alpha_{\pi}\left(\pi_{t-1}-\bar{\pi}\right)+\alpha_{y}\left[y_{t-1}-\bar{x}_{t-1}-\phi\left(y_{t-2}-\bar{x}_{t-2}\right)\right]
\end{aligned}
$$

Equation (1) is the IS curve, where $y_{t}$ is the logarithm of real output (GDP), $\bar{y}_{t}$ is the logarithm of true potential output, $\rho_{t-1}$ is the lagged value of the ex ante long-term real interest rate, and $v_{t}$ is an iid shock to aggregate demand. I assume that private-sector agents are completely informed at all times regarding the level of true potential output. This can be justified in one of two ways: $(i)$ the private sector consists of a large number of identical firms each of which knows its own productive capacity, or $(i i)$ the process of aggregating over the distribution of firms yields an economy-wide description that is observationally equivalent to $(i)$. Private-sector agents have rational expectations; they know the form of the monetary policy rule (described below) and the Fed's estimate of potential output that is used as an input to the rule. The true output gap is given by $y_{t}-\bar{y}_{t}$. In steady-state, the output gap is zero which implies that $\bar{\rho}$ is the steady-state real interest rate.

Equation (2) defines true potential output, where $c_{i}$ and $\mu_{i}$ for $i=0,1,2$ represent the intercept and slope terms for a segmented linear trend with breakpoints at $t_{1}$ and $t_{2}$. The above specification implies that $\bar{y}_{t}$ is trend stationary but subject to infrequent shifts in level and/or slope. Perron (1989) shows that standard statistical tests cannot reject the hypothesis of a unit root in U.S. real output data when the true data generating mechanism is one of stationary fluctuations around a trend of the type described by equation (2). More recently, Dolmas, Raj, and Slottje (1999) argue that U.S. labor productivity is more accurately modeled by a deterministic trend with a sudden change in level and slope around 1973, rather than as a unit root process. For simplicity, the model abstracts from any direct link between the economy's trend growth rate $\mu_{i}$ and the steady-state real interest rate $\bar{\rho} .^{7}$ A sudden level shift (a change in $c_{i}$ ) would have no theoretical link to $\bar{\rho}$, however.

Equation (3) is the short-run Phillips curve, where $\pi_{t}$ is the fully observable inflation rate defined as the $\log$ difference of the price level (the GDP price index), $E_{t-1}$ is the expectation operator conditional on information available at time $t-1$, and $z_{t}$ is a "cost-push" shock. Equation (3) combines elements of a backward-looking Phillips curve with an expectational timing feature that can be motivated by the "sticky information" Phillips curve described by Mankiw and Reis (2001). The steady-state version of equation (3) implies that there is no steady-state trade-off between inflation and real output.

Equation (4) summarizes the expectations theory of the term structure for an economy where

\footnotetext{
${ }^{7}$ In a model with optimizing private-sector agents, the balanced-growth version of the intertemporal consumption Euler equation would imply $\left[\left(1+\mu_{i}\right) /(1+n)\right]^{\sigma}=\beta[(1-\tau) \bar{\rho}+1]$, where $n \geq \mathbf{0}$ is the population growth rate, $\sigma>\mathbf{0}$ is the inverse of the elasticity of intertemporal substitution, $\beta \in(\mathbf{0}, 1)$ is the subjective discount factor, and $\tau \in[\mathbf{0}, 1]$ is the marginal tax rate.
} 
the "long-term" interest rate corresponds to a two-period Treasury security (the 6-month T-Bill). When combined with the $t-1$ dating of agents' expectations, the simple two-period term structure facilitates a closed-form solution to the model. Despite its simplicity, this setup is arguably more general than models in which only the one-period rate matters for aggregate demand. Privatesector agents use their knowledge of the Fed's policy rule to compute the expectation $E_{t-1} r_{t}$. In steady-state, equation (4) implies the Fisher relationship: $\bar{r}=\bar{\rho}+\bar{\pi}$.

Equation (5) is the Federal Reserve policy rule, where $\bar{\pi}$ the determines the steady-state inflation rate. The symbol $\bar{x}_{t}$ represents the Fed's real-time estimate of $\bar{y}_{t}$. This estimate is constructed by running a regression on the historical sequence of real output data $\left\{y_{s}\right\}_{s=t}^{s=t}$ which is fully observable. Fed policymakers in the model cannot directly observe true potential output $\bar{y}_{t}$ or the shocks $v_{t}$ and $z_{t}$. The hidden nature of the shocks is crucial because it prevents policymakers from using any knowledge they may have about the structure of the economy to back-solve for $\bar{y}_{t}$. The assumption of asymmetric information between the private-sector and the central bank is consistent with some recent papers that investigate the performance of alternative policy rules in environments where the gap that appears in the policy rule is subject to exogenous stochastic shocks. These shocks are interpreted as "noise" or "measurement error." 8 Unlike these exercises, however, the gap error in this model (given by $\bar{y}_{t}-\bar{x}_{t}$ ) is wholly endogenous - it depends on the structure of the economy, the form of the policy rule, and the algorithm used by the Fed to construct the $\left\{\bar{x}_{t}\right\}$ series. In this respect, the approach used here has features in common with models where the central bank uses its knowledge of the structure of the economy to solve a signal extraction problem when potential output (or the natural rate of unemployment) is unobservable. ${ }^{9}$

Equation (5) captures most of rule specifications that have been studied in the recent monetary policy literature. A simple version of the original Taylor (1993) rule can be represented by $\alpha_{\pi}=1.5$, $\alpha_{y}=0.5$, and $\alpha_{r}=\phi=0 .{ }^{10}$ Taylor (1999) considers a modified version of this rule which is characterized by a stronger response to the output gap, i.e., $\alpha_{y}=1.0$ rather than $\alpha_{y}=0.5$. In the appendix, I show that a nominal income growth rule can be obtained by setting $\alpha_{\pi}=\alpha_{y}$ with $\phi=1$ and $\alpha_{r}=0$.

The policy rule specification implies that the Fed reacts only to lagged variables and not to contemporaneous variables. This feature addresses the point made by McCallum (1999) that policy rules should be "operational," i.e., rules should reflect the fact that policy decisions must often be made before economic data for the current quarter become available. Finally, as in most quantitative studies of monetary policy rules, I abstract from the zero lower bound on nominal interest rates. ${ }^{11}$

\footnotetext{
${ }^{8}$ See, for example, Orphanides, et. al. (2000) and Rudebusch (2002).

${ }^{9}$ Examples include Weiland (1998), Svensson and Woodford (2000), Hansen and Sargent (2001, Chapter 8), and Cukierman and Lippi (2001), among others.

10 The original Taylor (1993) rule assumes that the funds rate responds to the average inflation rate over the past four quarters whereas equation (5) implies that the funds rate responds to inflation in the most recent quarter only.

${ }^{11}$ Imposing this nonlinear constraint during the stochastic simulations can lead to a runaway deflation if a particular sequence of random shocks brings about the condition $\rho_{t}>\bar{\rho}$ when $r_{t}=\mathbf{0}$ and $\pi_{t}<\mathbf{0}$.
} 


\subsection{The Fed's Real-Time Estimate of Potential Output}

Fed policymakers in the model construct a current, or "real-time," estimate of potential output by running a regression on the historical sequence of real output data. The regression algorithm can be viewed as part of the Fed's policy rule. In choosing an algorithm, I assume that policymakers wish to guard against the possibility that trend output may undergo structural shifts. ${ }^{12}$ This feature is achieved through the use of an algorithm that assigns more weight to recent data in constructing the end-of-sample estimate $\bar{x}_{t}$. The result is a flexible trend that can adapt to shifts in true potential output. The Fed's real-time potential output series is updated each period so that policymakers continually revise their view of the past as new observations arrive.

Given the historical sequence of real output data $\left\{y_{s}\right\}_{s=t_{0}}^{s=t}$, I assume that the Fed constructs the $\left\{\bar{x}_{t}\right\}$ series each period using one of the following three algorithms: discounted least squares (DLS), moving-window least squares (MWLS), or the Hodrick-Prescott (HP) filter.

DLS minimizes the sum of squared differences between a linear trend and a transformed version of the actual series that discounts past observations at a constant rate. As with the other two regression algorithms discussed below, DLS introduces an additional parameter that is directly analogous to the "gain" in a recursive learning algorithm. In this case, the additional parameter is the discount factor $\beta \in(0,1]$ which corresponds to a constant gain of $1-\beta$. Constant-gain learning algorithms imply that agents systematically downgrade (or forget) past data. ${ }^{13}$

MWLS minimizes the sum of squared differences between a linear trend and the actual series over a moving sample period. In this case, the additional parameter is the length of the moving window $T_{w} \geq 2$. Data outside the window is completely ignored. Friedman (1979) shows that this algorithm implies a decreasing gain sequence for observations inside the window, followed by a sharply increasing gain as the sample period moves forward. ${ }^{14}$

The HP filter minimizes the sum of squared differences between trend and the actual series, subject to a penalty term that constrains the size of the second differences. ${ }^{15}$ In this case, the additional parameter is the weight $\lambda$ assigned to the penalty term. The value of $\lambda$ controls smoothness of the resulting trend. When $\lambda=1600$, the HP filter approximates a band-pass filter that extracts components of quarterly data that are typically associated with business cycles or high-frequency noise, i.e., components with fluctuations between 2 and 32 quarters. St. Amant and van Norden (1997) show that when $\lambda=1600$, the HP filter assigns a weight of 20 percent to observations at the end of the sample, whereas observations at the center of the sample receive no more than a 6 percent weight. In describing the HP filter, Kydland and Prescott (1990, p. 9) claim that "the

\footnotetext{
${ }^{12}$ See Parry (2000) for some evidence that real-world policymakers guard against the possibility of trend shifts.

${ }^{13}$ Sargent (1999) employs a constant-gain learning algorithm in a model where the central bank estimates the slope of the long-run Phillips curve.

${ }^{14}$ Fuhrer and Hooker (1993) employ a MWLS algorithm in a model where private-sector agents must learn about shifts in the parameters of the monetary policy rule.

${ }^{15}$ For details, see Hodrick and Prescott (1997).
} 
implied trend path for the logarithm of real GNP is close to one that students of business cycles and growth would draw through a time plot of this series..."

One might argue that Fed policymakers could obtain a more-accurate estimate of true potential output by taking into account observations of other variables, such as inflation, or by solving an optimal signal extraction problem. I choose not to pursue these options here because their application hinges on the assumption that Fed policymakers possess detailed knowledge about key structural features of the economy such as the slope of the short-run Phillips curve or the distributions governing unobservable shocks. Given that simple univariate algorithms are commonly used to define potential output in monetary policy research (see, for example, Taylor 1999), the idea that Fed policymakers would adopt similar techniques does not seem unreasonable.

\subsection{Reduced-Form Version of the Model}

Taking private-sector expectations of both sides of equation (3), iterating forward and then taking expectations again yields

$$
\begin{aligned}
E_{t-1} \pi_{t} & =\pi_{t-1}+2 \gamma\left(y_{t-1}-\bar{y}_{t-1}\right), \\
E_{t-1} \pi_{t+1} & =E_{t-1} \pi_{t}+2 \gamma E_{t-1}\left(y_{t}-\bar{y}_{t}\right) .
\end{aligned}
$$

Taking private-sector expectations of both sides of equation (1) yields

$$
E_{t-1}\left(y_{t}-\bar{y}_{t}\right)=a_{1}\left(y_{t-1}-\bar{y}_{t-1}\right)+a_{2}\left(y_{t-2}-\bar{y}_{t-2}\right)+a_{\rho}\left(\rho_{t-1}-\bar{\rho}\right) .
$$

Since $r_{t}$ is a pre-determined variable, equation (5) implies $E_{t-1} r_{t}=r_{t}$. Substituting equations (5) through (8) into the term structure equation (4) and then solving for $\rho_{t-1}-\bar{\rho}$ yields

$$
\begin{aligned}
& \rho_{t-1}-\bar{\rho}=\left[\begin{array}{llll}
\frac{\alpha_{y} / 2-\gamma\left(a_{1}+2\right)}{1+\gamma a_{\rho}} & \frac{-\left(\gamma a_{2}+\alpha_{y} \phi / 2\right)}{1+\gamma a_{\rho}} & \frac{\alpha_{\pi} / 2-1}{1+\gamma a_{\rho}} & \frac{\left(1+\alpha_{r}\right) / 2}{1+\gamma a_{\rho}}
\end{array}\right]\left[\begin{array}{l}
y_{t-1}-\bar{y}_{t-1} \\
y_{t-2}-\bar{y}_{t-2} \\
\pi_{t-1}-\bar{\pi} \\
r_{t-1}-(\bar{\rho}+\bar{\pi})
\end{array}\right] \\
& +\quad\left[\begin{array}{ll}
\frac{\alpha_{y} / 2}{1+\gamma a_{\rho}} & \frac{-\alpha_{y} \phi / 2}{1+\gamma a_{\rho}}
\end{array}\right]\left[\begin{array}{l}
\bar{y}_{t-1}-\bar{x}_{t-1} \\
\bar{y}_{t-2}-\bar{x}_{t-2}
\end{array}\right],
\end{aligned}
$$

where the last two terms capture the influence of the Fed's real-time errors in measuring potential output. Substituting equation (9) into equation (1) and collecting ter ms yields the following reducedform version of the IS equation:

$$
\begin{aligned}
y_{t}-\bar{y}_{t}= & {\left[\begin{array}{llll}
\frac{a_{1}+a_{\rho}\left(\alpha_{y} / 2-2 \gamma\right)}{1+\gamma a_{\rho}} & \frac{a_{2}-a_{\rho} \alpha_{y} \phi / 2}{1+\gamma a_{\rho}} & \frac{a_{\rho}\left(\alpha_{\pi} / 2-1\right)}{1+\gamma a_{\rho}} & \frac{a_{\rho}\left(1+\alpha_{n}\right) / 2}{1+\gamma a_{\rho}}
\end{array}\right]\left[\begin{array}{l}
y_{t-1}-\bar{y}_{t-1} \\
y_{t-2}-\bar{y}_{t-2} \\
\pi_{t-1}-\bar{\pi} \\
r_{t-1}-(\bar{\rho}+\bar{\pi})
\end{array}\right] } \\
& +\left[\begin{array}{lll}
1 & \frac{a_{\rho} \alpha_{y} / 2}{1+\gamma a_{\rho}} & \frac{-a_{\rho} \alpha_{y} \phi / 2}{1+\gamma a_{\rho}}
\end{array}\right]\left[\begin{array}{c}
v_{t} \\
\bar{y}_{t-1}-\bar{x}_{t-1} \\
\bar{y}_{t-2}-\bar{x}_{t-2}
\end{array}\right]
\end{aligned}
$$


From the last two terms of equation (10), we can see that the policy rule parameters $\alpha_{y}$ and $\phi$ and the "structural" parameters $a_{p}$ and $\gamma$ are important for transmitting the Fed's real-time measurement errors to the true output gap $y_{t}-\bar{y}_{t}$. Two other parameters can also play a role. These are the weight of $1 / 2$ used in equations (3) and (4) and the regression parameter (either $\beta$, $T_{w}$, or $\lambda$ ) used by the Fed to construct the $\left\{\bar{x}_{t}\right\}$ series. The real-time measurement errors turn out to be strongly autocorrelated in the quantitative simulations. In such an environment, the virtue of a nominal income growth rule becomes clear: setting $\phi=1$ in equation (10) allows successive measurement errors to offset one another.

Substituting equation (6) into equation (3) yields the following reduced-form Phillips curve:

$$
\pi_{t}=\pi_{t-1}+2 \gamma\left(y_{t-1}-\bar{y}_{t-1}\right)+z_{t}
$$

which shows that the Fed's real-time measurement errors affect inflation only indirectly via their influence on the true output gap $y_{t}-\bar{y}_{t}$.

It is useful to rewrite the Fed's policy rule, equation (5), as

$$
\begin{aligned}
r_{t}-(\bar{\rho}+\bar{\pi})= & {\left[\begin{array}{llll}
\alpha_{y} & -\alpha_{y} \phi & \alpha_{\pi} & \alpha_{r}
\end{array}\right]\left[\begin{array}{l}
y_{t-1}-\bar{y}_{t-1} \\
y_{t-2}-\bar{y}_{t-2} \\
\pi_{t-1}-\bar{\pi} \\
r_{t-1}-(\bar{\rho}+\bar{\pi})
\end{array}\right] } \\
& +\quad\left[\begin{array}{ll}
\alpha_{y} & -\alpha_{y} \phi
\end{array}\right]\left[\begin{array}{l}
\bar{y}_{t-1}-\bar{x}_{t-1} \\
\bar{y}_{t-2}-\bar{x}_{t-2}
\end{array}\right]
\end{aligned}
$$

where the last two terms show how the Fed's real-time measurement errors influence the setting of the current funds rate. An econometrician who uses final data to estimate the Fed's policy rule is implicitly imposing the restriction $\bar{x}_{t}=\bar{y}_{t}$ for all $t$. This restriction causes the last two terms in equation (12) to drop out, thereby creating a missing variable problem. Empirical estimates of the Fed's policy rule typically find that the coefficient $\alpha_{r}$ on the lagged federal funds rate is around 0.8 and strongly significant. Rather than reflecting some form of policy inertia or interest-rate smoothing behavior, the lagged funds rate may actually be picking up the Fed's serially correlated real-time measurement errors which are not taken into account by the standard estimation procedure. Using the above model as a data-generating mechanism, Lansing (2002) shows that efforts to identify the Fed's policy rule using final data (as opposed to real-time data) can create the illusion of interest rate smoothing behavior when in fact none exists.

The reduced-form version of the full-information model is defined by equations (10), (11), and (12) with $\bar{x}_{t}=\bar{y}_{t}$ for all $t$. The reduced-form version of the learning model is defined by equations $(10),(11)$, and (12), together with the regression algorithm that defines the $\left\{\bar{x}_{t}\right\}$ series from observations of $\left\{y_{s}\right\}_{s=t_{0}}^{s=t}$. 


\subsection{The Fed's Perceived Shocks}

In this model, the Fed's policy rule is taken as given. Hence I do not need to assume that the Fed knows the structure of the economy defined by equations (1) through (4). The only information the Fed needs to do its job is historical data on interest rates, inflation, and output. Nevertheless, it is useful to consider the case where the Fed does know the structure of the economy and applies this information in an attempt to infer the size of the unobservable shocks $v_{t}$ and $z_{t}$. For this exercise, I assume that the Fed makes use of its own series for potential output $\left\{\bar{x}_{t}\right\}$ which it believes to be accurate. The shocks perceived by the Fed in this way can be obtained by substituting $\bar{x}_{t}$ in place of $\bar{y}_{t}$ for all $t$ into the full-information solution of the model and then solving for the shocks. This procedure yields

$$
\begin{aligned}
v_{t}^{\mathrm{Fed}} & =v_{t}+\left[\begin{array}{lll}
1 & \frac{-a_{1}-a_{\rho}\left(\alpha_{y} / 2-2 \gamma\right)}{1+\gamma a_{\rho}} & \frac{-a_{2}+a_{\rho} \alpha_{y} \phi / 2}{1+\gamma a_{\rho}}
\end{array}\right]\left[\begin{array}{c}
\bar{y}_{t}-\bar{x}_{t} \\
\bar{y}_{t-1}-\bar{x}_{t-1} \\
\bar{y}_{t-2}-\bar{x}_{t-2}
\end{array}\right], \\
z_{t}^{\mathrm{Fed}} & =z_{t}-2 \gamma\left(\bar{y}_{t-1}-\bar{x}_{t-1}\right) .
\end{aligned}
$$

The above expressions show that errors in measuring potential output may cause $v_{t}^{\text {Fed }}$ and $z_{t}^{\text {Fed }}$ to exhibit autocorrelation when in fact $v_{t}$ and $z_{t}$ are $i d$. This point has implications for researchers who use their model to infer the laws of motion of stochastic shocks hitting the U.S. economy. Even if the model has the correct form, different assumptions about the Fed's real-time potential output series $\left\{\bar{x}_{t}\right\}$ can influence the properties of the inferred shocks.

\section{Calibration and Estimation}

The reduced-form IS curve, equation (10), shows that Lucas's (1976) econometric policy critique applies to this model: All five of the policy rule parameters $\left(\alpha_{r}, \alpha_{\pi}, \alpha_{y}, \phi, \bar{\pi}\right)$ appear in the reducedform. Equation (10) also shows that failure to take into account the Fed's real-time measurement errors will lead to an omitted variable problem; the last two terms will drop out if one assumes $\bar{x}_{t}=\bar{y}_{t}$ for all $t$ as in the full-information model. To properly estimate the learning model's "structural" parameters $\left(a_{1}, a_{2}, a_{\rho}, \bar{\rho}, \gamma\right)$, one must construct the historical series $\left\{\bar{x}_{t}\right\}$ and then either $(i)$ allow the data to identify the policy rule parameters by including equation (5) in the system to be estimated or (ii) take a stand on the policy rule parameters and impose these as

restrictions on the rest of the system. Here I adopt the second approach and consider the following two parameterizations of equation (5):

Table 1: Policy Rule Parameters for Simulations

\begin{tabular}{lccccc}
\hline \hline & $\alpha_{r}$ & $\alpha_{\pi}$ & $\alpha_{y}$ & $\phi$ & $\bar{\pi}$ \\
\hline Taylor-type Rule & 0 & 1.5 & 1.0 & 0 & 0.042 \\
Nominal Income Growth Rule & 0 & 1.5 & 1.5 & 1 & 0.042 \\
\hline
\end{tabular}


The first rule in Table 1 is a modified version of the rule originally proposed by Taylor (1993). The modified version, analyzed by Taylor (1999), involves a stronger response to the output gap. Both versions of the Taylor rule assumed $\bar{\pi}=0.02$. Since my objective here is to determine how well the model can account for low-frequency movements in U.S. inflation over several decades, as opposed to more recent low-inflation periods, I set $\bar{\pi}=0.042$ to match the sample mean of U.S. inflation from 1966:1 to 2001:4. Nominal income growth rules that employ the short-term interest rate as an instrument have been advocated by McCallum (1999), McCallum and Nelson (1999), and Orphanides (1999), among others. To examine the performance of such a rule, I set $\alpha_{\pi}=\alpha_{y}=1.5$ with $\phi=1$. As with the Taylor rule, this parametrization provides a reasonably good fit of the U.S. federal funds rate during the low inflation era of the 1980s and 1990s.

As shown in Figure 1, the series for true potential output $\bar{y}_{t}$ is defined by a segmented linear trend fitted to U.S real GDP data of vintage 2002:1, as described in Croushore and Stark (1999). The sample starts at $t_{0}=1947: 1$. I allow for two structural breaks at $t_{1}=1973: 4$ and $t_{2}=1995: 4$. The first breakpoint is consistent with research on the dating of the 1970s productivity slowdown. The dating of the second breakpoint is consistent with the analyses of Oliner and Sichel (2000) and Gordon (2000) and is intended to capture the start of the so-called "new economy." In Figure 1, the postulated new-economy break involves a slope change only; there is no attendant shift in the level of potential output. An unrestricted linear regression over the period 1996:1 to 2001:4 would imply a downward shift in the level of U.S. potential output at 1995:4. This outcome seems inconsistent with the mainstream new-economy view that I am trying to capture here. Allowing for a downward shift in the level of potential output at 1995:4 has a negligible impact on the quantitative results.

Orphanides and van Norden (1999) show that unforeseen changes in the trajectory of the economy, not published data revisions, are the primary source of error in real-time measures of the output gap. Since changes in trajectory are the error source in this model, I adopt a "quasi-real time" method of constructing the historical series $\left\{\bar{x}_{t}\right\}$ for the period 1966:1 to 2001:4. This is done by rolling through the vintage 2002:1 real GDP data (starting with the subsample 1947:1 to 1966:1) and successively applying one of the three algorithms described in Section 2.1. Before doing this, however, I must assign a value to the regression parameter introduced by each algorithm, i.e., $\beta$ for DLS, $T_{w}$ for MWLS, and $\lambda$ for the HP filter. Since there are no standard values for $\beta$ and $T_{w}$, I calibrate these such that the low-frequency component of model inflation in the simulations peaks around 1979:2. ${ }^{16}$ The calibrated values differ across the two policy rule specifications and are shown in Table 2. In the case of the HP filter, it is standard practice to use $\lambda=1600$ for quarterly data so I adopt this value for both policy rule specifications. Interestingly, this value of $\lambda$ also causes the low frequency component of inflation to peak around 1979:2.

\footnotetext{
${ }^{16}$ Since $\beta$ and $T_{w}$ must be chosen before estimating the structural parameters and conducting the simulations, this outcome is achieved through trial and error.
} 
Given the policy rule parameters in Table 1, equations (10) and (11) are jointly-estimated by maximum likelihood. The results are summarized in Table 2.

Table 2: Maximum Likelihood Parameter Estimates, 1966:1 to 2001:4

\begin{tabular}{|c|c|c|c|c|}
\hline & \multicolumn{4}{|c|}{ Taylor-type rule: $\alpha_{r}=0, \alpha_{\pi}=1.5, \alpha_{y}=1.0, \phi=0, \bar{\pi}=0.042$} \\
\hline & \multirow{3}{*}{$\begin{array}{l}\text { Full-information model: } \\
\qquad \bar{x}_{t}=\bar{y}_{t}\end{array}$} & \multicolumn{3}{|c|}{ Learning model: $\bar{x}_{t}$ constructed by } \\
\hline & & DLS & MWLS & HP filter \\
\hline & & $\beta=0.875$ & $T_{w}=24$ & $\lambda=1600$ \\
\hline \multirow[b]{2}{*}{$a_{1}$} & 1.234 & 1.217 & 1.196 & 1.208 \\
\hline & $(0.073)$ & $(0.072)$ & $(0.071)$ & $(0.072)$ \\
\hline \multirow[b]{2}{*}{$a_{2}$} & -0.267 & -0.161 & -0.165 & -0.156 \\
\hline & $(0.073)$ & $(0.075)$ & $(0.075)$ & $(0.075)$ \\
\hline \multirow[b]{2}{*}{$a_{p}$} & -0.166 & -0.193 & -0.164 & -0.184 \\
\hline & $(0.039)$ & $(0.035)$ & $(0.030)$ & $(0.033)$ \\
\hline \multirow[b]{2}{*}{$\gamma$} & 0.046 & 0.046 & 0.046 & 0.046 \\
\hline & $(0.021)$ & $(0.021)$ & $(0.021)$ & $(0.021)$ \\
\hline \multirow[b]{2}{*}{$\bar{\rho}$} & 0.029 & 0.030 & 0.030 & 0.029 \\
\hline & $(0.008)$ & $(0.007)$ & $(0.008)$ & $(0.007)$ \\
\hline
\end{tabular}

Nominal income growth rule: $\alpha_{r}=0, \alpha_{\pi}=1.5, \alpha_{y}=1.5, \phi=1, \bar{\pi}=0.042$

\begin{tabular}{ccccc} 
& & \multicolumn{2}{c}{ Learning model: $\bar{x}_{t}$ constructed by } \\
& Full-information model: & DLS & MWLS & HP filter \\
& $\bar{x}_{t}=\bar{y}_{t}$ & $\beta=0.950$ & $T_{w}=44$ & $\lambda=1600$ \\
\hline \multirow{2}{*}{$a_{1}$} & 1.276 & 1.288 & 1.280 & 1.306 \\
& $(0.074)$ & $(0.074)$ & $(0.074)$ & $(0.077)$ \\
\hline \multirow{2}{*}{$a_{2}$} & -0.391 & -0.393 & -0.382 & -0.404 \\
& $(0.073)$ & $(0.074)$ & $(0.074)$ & $(0.076)$ \\
\hline \multirow{2}{*}{$a_{p}$} & -0.166 & -0.158 & -0.151 & -0.145 \\
& $(0.039)$ & $(0.039)$ & $(0.039)$ & $(0.039)$ \\
\hline \multirow{2}{*}{$\gamma$} & 0.046 & 0.046 & 0.046 & 0.046 \\
& $(0.021)$ & $(0.021)$ & $(0.022)$ & $(0.021)$ \\
\hline \multirow{2}{*}{$\bar{\rho}$} & 0.029 & 0.028 & 0.028 & 0.028 \\
& $(0.008)$ & $(0.008)$ & $(0.009)$ & $(0.009)$ \\
\hline \hline
\end{tabular}

Notes: For estimation purposes, true potential output $\bar{y}_{t}$ is defined by a segmented linear trend fitted to U.S real GDP data of vintage 2002:1. The data are described by Croushore and Stark (1999). The three segments, shown in Figure 1, run from 1947:1 to $1973: 4,1974: 1$ to $1995: 4$, and 1996:1 to 2001:4. For the learning model, the $\left\{\bar{x}_{t}\right\}$ series is constructed in quasi-real time by rolling through the vintage 2002:1 real GDP data starting with the subsample 1947:1 to 1966:1 and successively applying one of the following trend estimation algorithms: discounted least squares (DLS) with a discount factor $\beta$, moving-window least squares (MWLS) with a window length $T_{w}$, and the Hodrick-Prescott (HP) filter with a smoothing parameter $\lambda$. 
The parameter estimates for the full-information model differ somewhat from those of the learning model when the Taylor-type rule is imposed, but not when the nominal income growth rule is imposed. The point estimate for $a_{2}$ exhibits substantial variation across the two policy rule specifications but the point estimates for the other parameters are reasonably close. For the stochastic simulations, I adopt parameter values that lie approximately midway between those estimated for the two policy rule specifications. I calibrate the standard deviations of the two izd shocks $v_{t}$ and $z_{t}$ such that the standard deviations of $\left(y_{t}-\bar{y}_{t}\right)$ and $\pi_{t}$ in the model are close to the corresponding values in U.S. data over the period 1966:1 to 2001:4. Table 3 summarizes the parameter values used in the simulations.

Table 3: Structural Parameters for Simulations

\begin{tabular}{ccccccc}
\hline \hline$a_{1}$ & $a_{2}$ & $a_{p}$ & $\gamma$ & $\bar{\rho}$ & $\sigma_{v}$ & $\sigma_{z}$ \\
\hline 1.25 & -0.35 & -0.20 & 0.046 & 0.030 & 0.0045 & 0.0050 \\
\hline \hline
\end{tabular}

\section{Quantitative Simulations}

Figure 3 plots the hypothetical interest rate paths generated by each policy rule under the assumption that the Fed can observe true potential output in real time, i.e., $\bar{x}_{t}=\bar{y}_{t}$ for all $t$. I use vintage 2002:1 data and the potential output series defined by the linear segmented trend fitted to U.S real GDP. The policy rule parameters are taken from Table 1 , with $\bar{\rho}=0.03$. A comparison of the hypothetical path implied by the Taylor-type rule to the actual path of the U.S. federal funds rate reveals the basis for the "policy mistake" view of the 1960s and 1970s discussed by Taylor (1999) and others. In particular, the U.S federal funds rate appears to be systematically below the path recommended by the Taylor-type rule. This suggests that monetary policy was too loose during this period and at least partially responsible for the Great Inflation. During the 1980s and 1990s, however, the actual path of the funds rate conforms much more closely to the rule's recommendations. $^{17}$ The hypothetical path implied by the nominal income growth rule tells much the same story but, in agreement with the findings of Orphanides (1999), provides a better fit of the actual funds rate path during the early 1980s. This suggests that a nominal income growth rule could have avoided what appears to be a second policy mistake during the years 1982 to 1984 when the actual federal funds rate is much higher than the level called for by the Taylor-type rule.

Orphanides (1999) argues that historical interpretations based on plots such as Figure 3 are misleading because they fail to take into account the information that was available to Fed policymakers in real time. He shows that estimates of potential output constructed by the Council of Economic Advisers imply a real-time output gap of -15 percent in 1975 versus only about -5 percent using final (vintage 1994:4) data. In simulations, he finds that the Taylor (1993) rule driven

\footnotetext{
${ }^{17}$ Taylor (1999, section 7.3.2) describes the the evolution of the Fed's policy rule as the result of a gradual learning process of how best to conduct monetary policy.
} 
by the Council's potential output series and real-time inflation and output data can generate a path for the federal funds rate that tracks amazingly well with the actual historical path from the mid 1960s to around 1980. Finally, he suggests that a shift in the Fed's policy rule to one based on nominal income growth may provide an explanation for the declining path of U.S inflation during the 1980s.

Taylor (2000) argues that the Council's estimates of potential output were highly politicized as early as the 1960s and hence were ignored by serious economists such as Arthur Burns and Alan Greenspan. Taylor also argues that the real-time output gaps derived from the Council's estimates (e.g., -15 percent in 1975) are implausibly large; taken at face value, these figures imply that Fed policymakers of the 1970s believed they were experiencing a calamity on the order of the Great Depression. To address such arguments, this paper employs a real-time potential output series that is constructed inside the model using a simple and plausible regression algorithm.

In the quantitative simulations, I focus on the model's predictions for the low-frequency (longterm) movements in inflation. Thus I allow room for the oil and food price shocks emphasized by Blinder (1982) to have played a role in generating the actual time series of U.S. inflation. Given current research on the dating of a trend break in U.S. labor productivity, I examine changes in trend inflation after 1973.

For each of the two policy rule specifications, I simulate the model 1000 times with shock realizations drawn randomly from independent normal distributions with the standard deviations shown in Table 3. I assume that the Fed uses the same policy rule (either the Taylor-type rule or the nominal income growth rule) throughout the entire simulation. Each simulation starts from the steady state at $t_{0}=1947: 1$ and runs for 220 periods (the number of quarters from 1947:1 to 2001:4). Fuhrer and Moore (1995) argue that the federal funds rate can be viewed as the primary instrument of monetary policy only since the mid-1960s. Before then, the funds rate traded below the Federal Reserve discount rate. Based on this reasoning, the Fed's regression algorithm for constructing the $\left\{\bar{x}_{t}\right\}$ series is placed in service at 1966:1. Prior to this date, I set $\bar{x}_{t}=\bar{y}_{t}$ for all $t$. Hence I assume that the U.S. economy was fluctuating around its steady state before the Fed sought to exert control through the federal funds rate in the mid-1960s. Occasionally, a particular sequence of shock realizations will cause the nominal interest rate to become negative. Overall, however, I find that this occurs in only about 3 to 5 percent of the periods during the simulations (depending on the policy rule and the Fed's regression algorithm). The results of the simulations are summarized in Tables 4 and 5 and Figures 4 through 7. 
Table 4: Summary Statistics from 1000 Simulations

\begin{tabular}{|c|c|c|c|c|}
\hline Variable & $\begin{array}{l}\text { U.S. } \\
\text { Data }\end{array}$ & $\begin{array}{c}\alpha_{r}=0, \alpha_{\pi}= \\
\text { DLS } \\
\beta=0.875\end{array}$ & $\begin{array}{c}\text { ylor-type } \\
\alpha_{y}=1.0 \\
\text { MWLS } \\
T_{w}=24\end{array}$ & $\begin{array}{l}0, \bar{\pi}=0.042 \\
\text { HP filter } \\
\lambda=1600\end{array}$ \\
\hline$\Delta \pi_{73: 4-79: 2}$ & 1.65 & 1.29 & 1.44 & 1.24 \\
\hline$\Delta \pi_{79: 2-86: 2}$ & -5.59 & -1.79 & -2.45 & -2.11 \\
\hline$\Delta \pi_{95: 4-01: 4}$ & -0.68 & -0.77 & -1.76 & -1.54 \\
\hline $\operatorname{Std}\left[y_{t}-\bar{y}_{t}\right]$ & 2.24 & 2.21 & 2.59 & 2.46 \\
\hline $\operatorname{Std}\left[\pi_{t}\right]$ & 2.45 & 2.44 & 2.80 & 2.64 \\
\hline $\operatorname{Std}\left[\pi_{t}+y_{t}-y_{t-1}\right]$ & 3.78 & 2.79 & 2.98 & 2.87 \\
\hline $\operatorname{Std}\left[r_{t}\right]$ & 3.07 & 3.30 & 3.78 & 3.59 \\
\hline $\operatorname{Std}\left[\Delta r_{t}\right]$ & 1.11 & 0.90 & 0.95 & 0.93 \\
\hline \multirow[b]{2}{*}{ Variable } & & \multicolumn{3}{|c|}{$\begin{array}{l}\text { Nominal income growth rule } \\
0, \alpha_{\pi}=1.5, \alpha_{y}=1.5, \phi=1, \bar{\pi}=0.042\end{array}$} \\
\hline & $\begin{array}{l}\text { U.S. } \\
\text { Data }\end{array}$ & $\begin{array}{c}\text { DLS } \\
\beta=0.950\end{array}$ & $\begin{array}{c}\text { MWLS } \\
T_{w}=44\end{array}$ & $\begin{array}{l}\text { HP filter } \\
\lambda=1600\end{array}$ \\
\hline$\Delta \pi 73: 4-79: 2$ & 1.65 & 0.91 & 0.86 & 0.39 \\
\hline$\Delta \pi_{79: 2-86: 2}$ & -5.59 & -0.95 & -1.26 & -0.65 \\
\hline$\Delta \pi_{95: 4-01: 4}$ & -0.68 & -0.44 & -0.66 & -0.14 \\
\hline $\operatorname{Std}\left[y_{t}-\bar{y}_{t}\right]$ & 2.24 & 2.22 & 2.33 & 2.68 \\
\hline $\operatorname{Std}\left[\pi_{t}\right]$ & 2.45 & 2.32 & 2.43 & 2.54 \\
\hline $\operatorname{Std}\left[\pi_{t}+y_{t}-y_{t-1}\right]$ & 3.78 & 2.62 & 2.67 & 2.61 \\
\hline $\operatorname{Std}\left[r_{t}\right]$ & 3.07 & 3.27 & 3.41 & 3.71 \\
\hline $\operatorname{Std}\left[\Delta r_{t}\right]$ & 1.11 & 1.29 & 1.29 & 1.31 \\
\hline
\end{tabular}

Notes: $\Delta \pi$ is the change in trend inflation between the indicated dates where trend is defined by the low-frequency component (fluctuations with period $\geq 8$ years) isolated by the band pass filter approximation described by Christiano and Fitzgerald (1999). Std = standard deviation in percent for the sample period 1966:1 to 2001:4 averaged over 1000 simulations. $y_{t}=\log$ of real output (GDP), $\bar{y}_{t}=\log$ of true potential output defined by segmented linear trend, $\pi_{t}=$ inflation rate (based on GDP Price index), $\pi_{t}+y_{t}-y_{t-1}=$ observed nominal income growth (annualized), $r_{t}=$ one period nominal interest rate (federal funds rate), $\Delta r_{t}=r_{t}-r_{t-1}$.

Table 5: Actual versus Perceived Shocks

\begin{tabular}{lcccc}
\hline \hline \multicolumn{2}{c}{ Taylor-type rule: $\alpha_{r}=0, \alpha_{\pi}=1.5, \alpha_{y}=1.0, \phi=0, \bar{\pi}=0.042$} \\
\multicolumn{1}{c}{ Variable } & Actual shocks & DLS & Fed's perceived shocks \\
& & $\beta=0.875$ & $T_{w}=24$ & $\lambda=1600$ \\
\hline Std $\left[v_{t}\right]$ & 0.448 & 0.536 & 0.581 & 0.564 \\
Std $\left[z_{t}\right]$ & 0.500 & 0.547 & 0.572 & 0.563 \\
Corr $\left[v_{t}, v_{t-1}\right]$ & -0.006 & 0.086 & 0.198 & 0.160 \\
Corr $\left[z_{t}, z_{t-1}\right]$ & -0.005 & 0.150 & 0.212 & 0.191 \\
Corr $\left[v_{t}, z_{t}\right]$ & -0.003 & -0.145 & -0.219 & -0.191 \\
\hline \hline
\end{tabular}

Notes: Statistics are averages over 1000 simulations.

The Fed's perceived shocks are computed using equations (13) and (14).

Std $=$ standard deviation (in percent) over the sample period 1966:1 to 2001:4.

Corr $=$ correlation coefficient over the sample period 1966:1 to 2001:4. 


\subsection{Changes in Trend Inflation}

Table 4 compares the low-frequency (trend) movements of U.S. inflation to those predicted by the model. The low-frequency component of U.S. inflation is more likely to be dominated by permanent shocks of the type considered here that alter the course of potential output forever. For both the model and the data, I use the band-pass filter approximation described by Christiano and Fitzgerald (1999) to isolate the component of inflation with fluctuations greater than 32 quarters (8 years). This methodolgy for comparing the model to the data is directly analogous to that used in the real business literature except that here I focus on the low-frequency component rather than on the business-cycle component. I examine changes in trend inflation during three periods of interest:

1973:4 to 1979:2 - from the start of the productivity slowdown to the peak in trend inflation.

1979:2 to 1986:2 - from the peak in trend inflation to the subsequent trough.

1995:4 to 2001:4 - from the start of the new economy to the end of the data sample.

From 1973:4 to 1979:2, the model with a Taylor-type rule yields an increase in trend inflation that can be compared to the 1.65 percentage point increase in the low-frequency component of U.S. inflation. ${ }^{18}$ For the model, the lar gest increase occurs under MWLS $\left(\Delta \pi_{73: 4-79: 2}=1.44\right)$, followed by DLS $\left(\Delta \pi_{73: 4-79: 2}=1.29\right)$, and then the HP filter $\left(\Delta \pi_{73: 4-79: 2}=1.24\right)$. A perfect match between the model and the data should perhaps not be expected because the model abstracts from any realtime errors in measuring real output $y_{t}$ or inflation $\pi_{t}$ (based on the GDP price index) which could have influenced Fed policy during the 1970s. Orphanides (2000) shows that real-time measures of real output and inflation were both too low in 1973. Such errors could have contributed to an overly-expansionary monetary policy, and hence an increase in trend inflation, beyond that which is due solely to the error in measuring potential output.

From 1979:2 to 1986:2, the low-frequency component of U.S. inflation declined by 5.59 percentage points. ${ }^{19}$ With a Taylor-type rule, the largest decline in trend inflation occurs under MWLS $\left(\Delta \pi_{79: 2-86: 2}=-2.45\right)$, followed by the HP filter $\left(\Delta \pi_{79: 2-86: 2}=-2.11\right)$, and then DLS $\left(\Delta \pi_{79: 2-86: 2}=-1.79\right)$. Notice that these figures are larger in magnitude than the initial increase in trend inflation from 1973:4 to 1979:2. Nevertheless, the model accounts for less than one-half of the decline in U.S. trend inflation after 1979:2. Recall, however, that the model abstracts from any change in the Fed's policy rule. Estrella and Fuhrer (2000) find strong evidence of a break in the monetary policy regime occurring sometime in the late 1970s. One way to model the policy rule change would be to impose an exogenous downward shift in the Fed's inflation target $\bar{\pi}$ ocurring around 1979. Imposing such a rule change, Huh and Lansing (2000) show that a model similar to this one (but without trend learning) can reasonably approximate the low-frequency movements in U.S. macro variables during the disinflation of the 1980s.

\footnotetext{
${ }^{18}$ The net increase in actual U.S. inflation from 1973:4 to $1979: 2$ was 2.21 percentage points.

${ }^{19}$ The net decrease in actual U.S. inflation from 1979:2 to $1986: 2$ was 7.12 percentage points.
} 
According to the model, the Fed's use of a nominal income growth rule during the 1970s could have prevented some of the increase in trend inflation that takes place under the previous scenario. With a nominal income growth rule, the largest increase in trend inflation occurs under DLS $\left(\Delta \pi_{73: 4-79: 2}=0.91\right)$, followed by MWLS $\left(\Delta \pi_{73: 4-79: 2}=0.86\right)$, and then the HP filter $\left(\Delta \pi_{73: 4-79: 2}=0.39\right)$. The explanation for the smaller numbers is straightforward. Since real-time errors in measuring potential output are autocorrelated, setting $\phi=1$ in equations (10) and (12) allows successive errors to largely cancel. It is important to note that I am stacking the deck against the nominal income growth rule in the case of DLS and MWLS because the regression parameters $\beta=0.95$ and $T_{w}=44$ are considerably larger in magnitude than those used in conjunction with the Taylor-type rule, i.e., $\beta=0.875$ and $T_{w}=24$. All else equal, larger values of $\beta$ and $T_{w}$ will cause the Fed's regression algorithm to place more emphasis on pre-slowdown data, thereby delaying the policymakers' discovery that trend output has shifted.

I also experimented with the policy rule advocated by Henderson and McKibbin (1993). This rule has the same form as the Taylor-type rule, but responds more strongly to inflation and the output gap as reflected by the following parameter values: $\alpha_{\pi}=\alpha_{y}=2.0, \alpha_{r}=\phi=0$. A larger value of $\alpha_{y}$ serves to magnify the hump-shaped pattern in trend inflation because the Fed cuts interest rates more aggressively when the perceived output gap is negative in the periods following the first trend shift at 1973:4. Under the Henderson-McKibbin rule with DLS and $\beta=0.875$, I obtained $\Delta \pi_{73: 4-79: 2}=1.66$ and $\Delta \pi_{79: 2-86: 2}=-3.14$. These results should be interpreted with caution, however, because the standard deviations of the model variables were generally much larger than their U.S. counterparts and the nominal interest rate was negative in about 7.5 percent of the periods during the simulations. A negative nominal interest rate would be observed even more frequently with an optimized version of equation (5) that miminizes the weighted sum of the unconditional variances of the model variables. Optimized rules of this sort typically call for a very strong response to inflation and the output gap. ${ }^{20}$

In order to provide a better sense of the model's dynamics, Figures 4 through 6 plot the average trajectories of the model variables for the case where the Fed's real-time measure of potential output is contructed using DLS. The corresponding average trajectories for the low-frequency components of the variables look nearly identical. Figures $4 \mathrm{~b}$ (Taylor-type rule) and Figure 5b (nominal income growth rule) show the divergence between the true gap and the perceived gap in the periods following the first trend shift at 1973:4. This divergence captures the size of the real-time measurement error. The divergence narrows over time as the Fed's regression algorithm detects the shift in trend ouput. Figure 7 shows that the regression algorithm exhibits overshooting behavior. The overshooting behavior helps to generate a more pronounced hump-shaped pattern in trend inflation. Under the Taylor-type rule, the average trajectory of the true gap $\left(y_{t}-\bar{y}_{t}\right)$ becomes negative during the

\footnotetext{
${ }^{20}$ For example, Lansing and Trehan (2001) show that the optimal discretionary rule for a model that resembles this one would imply $\alpha_{\pi}>2$ and $\alpha_{y}>2$.
} 
early $1980 \mathrm{~s}$ while the perceived gap $\left(y_{t}-\bar{x}_{t}\right)$ is close to zero or slightly positive (Figures $4 \mathrm{~b}$ ). This combination serves to bring down inflation faster in comparison to the trajectory observed under the nominal income growth rule where the true gap and the perceived gap approximately coincide starting in the mid 1980s.

In the periods following the first trend shift at 1973:4, the Fed's incoming data suggests that the economy is experiencing a recession but inflation is rising, not falling as might be expected from a standard Phillips-curve argument. The Fed interprets this combination of events (stagflation) to be caused by the simultaneous occurrence of a negative demand shock and adverse cost-push shock (Figures $4 \mathrm{c}$ and $5 \mathrm{c}$ ). The situation is reversed in the periods following the second trend shift at 1995:4; the incoming data suggests that the economy is experiencing a boom but inflation is headed downward. The Fed interprets this combination of events to be caused by a positive demand shock and a favorable cost-push shock.

Figure 6 shows that the model captures the lead-lag behavior of the U.S. variables shown earlier in Figure 2. Under both policy rules, the model output gap peaks before 1979:2 while the model interest rate peaks after 1979:2. From 1995:4 to 2001:4, the model produces a mild hump-shaped pattern in inflation and the interest rate. Similar movements can be also observed in U.S. data (Figures 2a and 2c). The model does not replicate the hump-shaped pattern in the U.S. output gap from 1995:4 to 2001:4, however (Figure $2 \mathrm{~b}$ )

By the time of the second trend shift at 1995:4, there is still a divergence between the true gap and the perceived gap under the Taylor-type rule (Figure 4b) but the divergence has nearly been eliminated under the nominal income growth rule (Figure 5b). Thus, different economic conditions prevail for the two policy rule scenarios when the new economy arrives in 1995:4. Under both policy rules, the model produces a decline in trend inflation after 1995:4. For the Taylortype rule, the largest decline occurs under MWLS $\left(\Delta \pi_{95: 4-01: 4}=-1.76\right)$, followed by the HP filter $\left(\Delta \pi_{95: 4-01: 4}=-1.54\right)$, and then DLS $\left(\Delta \pi_{95: 5-01: 2}=-0.77\right)$. From 1995:4 to 2001:4, trend inflation in U.S. data declined by 0.68 percentage points - very close to the model's prediction under DLS.

In the model, the decline in trend inflation after 1995:4 occurs for two reasons: $(i)$ because Fed policymakers raise the short-term interest rate in response to their perception of a widening output gap, and (ii) because the economy's productive capacity has truly expanded. One could argue that the model overstates the Fed's misperception of the output gap in the period after 1995:4 because real world policymakers were more alert to the possibility of a trend shift in the mid-to-late 1990s than they were in the 1970s. Introducing a more sophisticated learning algorithm into the model to capture this idea would reduce the Fed's misperception of the output gap and thus lead to smaller decline in trend inflation after 1995:4.

Since the Fed's learning algorithm is self-referential, policymakers can be whipsawed by a scenario where they cut interest rates very aggressively in the periods following the first trend shift but then 
do not reverse course in time to prevent the onset of explosive oscillations. My experiments show that this can occur for policy rules that respond strongly to the output gap (as measured by $\alpha_{y}$ ) or exhibit a large degree of interest-rate smoothing (as measured by $\alpha_{r}$ ). In such cases, oscillations can be dampened by reducing the weight assigned to the most recent data in the Fed's regression algorithm, that is, by adopting larger values for the regression parameters $\beta, T_{w}$, or $\lambda^{21}$

\subsection{Business Cycle Stabilization Properties}

Recent studies by Orphanides, et. al. (2000) and Rudebusch (2002) compare optimized Taylor-type rules with optimized nominal income growth rules in economies subject to output gap uncertainty. ${ }^{22}$ Both studies find that nominal income growth rules can outperform Taylor-type rules if the Fed's real-time errors in measuring the output gap are sufficiently large. Rule performance is measured by a weighted sum of the unconditional variances of selected model variables. There is an important distinction between the methodology of these studies and that used here. Specifically, these studies compare policy rule performance in an environment where the stochastic process governing the real-time measurement errors is exogenous and thus invariant to the policy rule. Such an approach opens the door to a subtle version of the Lucas critique: When monetary policy is formulated in real time, the stochastic process governing the real-time measurement errors is not policy invariant. Instead, the errors depend on the policy rule and the algorithm used by the Fed to construct a real-time potential output series. The algorithm itself can be viewed as part of the policy rule. This point can be illustrated by comparing Figure 4b to Figure 5b where we see that the pattern of divergence between the true gap and the perceived gap differs significantly across the two policy rule specifications. An advantage of the nominal income growth rule is its ability to dampen, rather than propagate, the real-time measurement errors.

In order to assess the business cycle stabilization properties of the two policy rules, Table 2 reports the standard deviations of the model variables. The stabilization properties of the two rules are broadly similar. The most notable difference concerns $\operatorname{Std}\left[\Delta r_{t}\right]$ which is around 1 percent for the Taylor-type rule versus 1.3 percent for the nominal income growth rule. The simulations involving the HP filter provide the most straightforward comparison because the gain parameter of the Fed's learning algorithm is held constant across the two policy rules. In this case, the Taylortype rule yields lower values for $\operatorname{Std}\left[y_{t}-\bar{y}_{t}\right], \operatorname{Std}\left[r_{t}\right]$, and $\operatorname{Std}\left[\Delta r_{t}\right]$, but higher values for $\operatorname{Std}\left[\pi_{t}\right]$ and $\operatorname{Std}\left[\pi_{t}+y_{t}-y_{t-1}\right]$. Any ranking of the performance of the two rules would thus depend on the particular criterion function adopted by the researcher (or the central bank)..$^{23}$

\footnotetext{
${ }^{21}$ This result is consistent with research that examines the impact of longer memory on the stability of learning equilibria in forward-looking economic models. See Barucci (2000) for learning algorithms based on DLs and Balasko and Royer (1996) for learning algorithms based on MWLS.

${ }^{22}$ Consistent with the procedure followed here, the Fed's perceived output gap is used as an input to the monetary policy rule while the true output gap influences aggregate demand and inflation.

${ }^{23}$ This point has been demonstrated formally by Jensen (2002).
} 
Table 5 shows that the average statistical properties of the Fed's perceived shocks are not too much different from the actual shocks. Thus if Fed policymakers have knowledge of the true distribution governing the shocks, they would be unlikely to conclude from casual observation that a particular sequence of perceived shocks did not come from the true distribution. Given that the actual shocks are assumed to be unobservable, it is probably unrealistic to assume that Fed policymakers have knowledge of the true distribution anyway. Indeed, this type of argument is used to motivate the robust control methods explored by Hansen and Sargent (2001).

\section{Concluding Remarks}

I constructed an artificial economy to investigate the degree to which sudden and unobserved shifts in trend output may have contributed to low-frequency movements in U.S. inflation. The experiments showed that the inability of Fed policymakers to observe the 1970s productivity slowdown in real time could have pushed up trend inflation by a nontrivial amount during latter part of the decade. Moreover, the Fed's gradual detection of the slowdown using simple econometric methods may help to explain why it took until 1979:2 before trend inflation peaked and started heading back down. My analysis focused on a single explanation of the Great Inflation in order to isolate the merits and drawbacks of a particular theory. It is likely, however, that elements from many different theories of the historical episode were operating simultaneously.

Model simulations using a postulated version of the so-called new economy predicted a decline in tend inflation after 1995:4 - a pattern that is also observed in U.S. data. Nevertheless, given the short sample of data available since 1995:4, there remains a great deal of uncertainty about whether

the U.S. economy's sustainable growth rate has actually increased. Future data observations will help us determine whether the new economy is a reality.

Overall, the results showed that a policy rule which incorporates some response to nominal income growth may be worth considering as a practical guide to Fed policymakers. The virtue of such a rule, as demonstrated in the simulations, is its built-in ability to guard for the possibility of unobserved trend shifts - a practice that Fed policymakers already engage in by less formal means. 


\section{A Appendix}

Here I show that a nominal income growth rule can be represented by a special case of equation (5). Imposing $\alpha_{\pi}=\alpha_{y}=\theta>0, \phi=1, \alpha_{r}=0$, and then rearranging yields

$$
r_{t}=\bar{\rho}+\bar{\pi}+\theta\left[\pi_{t-1}+y_{t-1}-y_{t-2}-\left(\bar{x}_{t-1}-\bar{x}_{t-2}\right)-\bar{\pi}\right] .
$$

where all rates are initially expressed on a quarterly basis. Quarterly inflation is given by $\pi_{t}=$ $\ln \left(P_{t} / P_{t-1}\right)$ for all $t$, where $P_{t}$ is the GDP price index. We also have $y_{t}=\ln Y_{t}$ for all $t$, where $Y_{t}$ is quarterly real GDP. Substituting these expressions into equation (A.1) and rearranging yields

$$
r_{t}=\bar{\rho}+\bar{\pi}++\theta\left[g_{t-1}-\left(\bar{x}_{t-1}-\bar{x}_{t-2}\right)-\bar{\pi}\right],
$$

where $g_{t-1} \equiv \ln \left(P_{t-1} Y_{t-1}\right)-\ln \left(P_{t-2} Y_{t-2}\right)$ is the observed quarterly growth rate of nominal income.

Recall that $\bar{x}_{t-1}$ and $\bar{x}_{t-2}$ represent the Fed's estimate of the logarithm of potential output for the periods $t-1$ and $t-2$, respectively. Both of these quantities are computed at $t-1$, however, because the Fed runs a regression each period and updates its entire potential output series. Since $\bar{x}_{t-1}$ and $\bar{x}_{t-2}$ both lie on the best-fit trend line computed at $t-1$, we have $\hat{\mu}_{t-1}=\bar{x}_{t-1}-\bar{x}_{t-2}$ where $\hat{\mu}_{t-1}$ is the Fed's real-time estimate of the quarterly growth rate of potential output. Substituting this expression into equation (A.2) yields

$$
r_{t}=\bar{\rho}+\bar{\pi}+\theta\left[g_{t-1}-\left(\hat{\mu}_{t-1}+\bar{\pi}\right)\right],
$$

which shows that the Fed will raise $r_{t}$ above its steady-state level whenever observed nominal income growth $g_{t-1}$ exceeds the target level of $\hat{\mu}_{t-1}+\bar{\pi}$. Multiplying both sides of equation (A.3) by 4 coverts all quarterly rates to an annual basis. 


\section{References}

[1] Balasko, Yves and Daniel Royer. (1996). "Stability of Competitive Equilibria with Respect to Recursive and Learning Processes," Journal of Economic Theory, 68, 319-348.

[2] Barucci, Emilio. (2000). "Exponentially Fading Memory Learning in Forward-Looking Economic Models," Journal of Economic Dynamics and Control, 24, 1027-1046.

[3] Blinder, Alan S. (1982). "The Anatomy of Double-Digit Inflation in the 1970s", in R. Hall, ed., Inflation: Causes and Effects, pp 261-282. Chicago: University of Chicago Press.

[4] Bomhoff, Eduard J. (1993). "Inflation in Western Europe," in K. Shigehara, ed., Price Stabilization in the 1990s, pp. 94-125. London: Macmillan.

[5] Christiano, Lawrence J. and Terry J. Fitzgerald. (1999). "The Band Pass Filter," National Bureau of Economic Research, Working Paper 7257.

[6] Croushore, Dean and Tom Stark. (1999) "A Real-Time Data Set for Macroeconomists: Does the Data Vintage Matter?" Federal Reserve Bank of Philadelphia, Working Paper 99-21. Available at $<$ www.phil.frb.org $>$

[7] Cukierman, Alex and Francesco Lippi. (2001). "Endogenous Monetary Policy with Unobserved Potential Output," Working Paper, Tel-Aviv Univsersity and Bank of Italy.

[8] Dolmas, Jim, Baldev Raj, and Daniel J. Slottje. (1999). "The U.S. Productivity Slowdown: A Peak Through a Structural Break Window," Economic Inquiry, 37, 226-241.

[9] Estrella, Arturo and Jeffrey C. Fuhrer. (2000). "Are 'Deep' Parameters Stable? The Lucas Critique as an Empirical Hypothesis," Federal Reserve Banks of New York and Boston, unpublished manuscript.

[10] Friedman, Benjamin M. (1979). "Optimal Expectations and the Extreme Information Assumptions of Rational Expectations Models," Journal of Monetary Economics, 5, 23-41.

[11] Fry, Maxwell J. (1993). "Inflation and Monetary Policy in Pacific Basin Developing Economies," in K. Shigehara, ed., Price Stabilization in the 1990s, pp. 137-164. London: Macmillan.

[12] Fuhrer Jeffrey C and Mark A. Hooker. (1993). "Learning About Monetary Regime Shifts in an Overlapping Wage Contract Model," Journal of Economic Dynamics and Control, 17, 531-553.

[13] Fuhrer Jeffrey C. and George Moore. (1995). Monetary Policy Trade-offs and the Correlation between Nominal Interest Rates and Real Output," American Economic Review, 85, 219-239.

[14] Galí, Jordi and Mark Gertler. (1999). "Inflation Dynamics: A Structural Econometric Analysis," Journal of Monetary Economics, 44, 195-222.

[15] Gordon, Robert J. (2000). "Does the 'New Economy' Measure Up to the Great Inventions of the Past?" Journal of Economic Perspectives, 14, 49-74.

[16] Hansen, Lars Peter and Thomas J. Sargent. (2001). Elements of Robust Control and Filtering for Macroeconomics, unpublished monograph.

[17] Henderson, Dale and Warwick J. McKibbon. (1993). "A Comparison of Some Basic Monetary Policy Regimes for Open Economies: Implications of Different Degrees of Instrument Adjustment and Wage Persistence," Carnegie Rochester Conference Series on Public Policy. $39,221-318$.

[18] Huh, Chan G. and Kevin J. Lansing. (2000). "Expectations, Credibility, and Disinflation in a Small Macroeconomic Model," Journal of Economics and Business, 52, 51-86.

[19] Hodrick, Robert J. and Edward C. Prescott. (1997). "Postwar U.S. Business Cycles: An Empirical Investigation," Journal of Money, Credit, and Banking, 29, 1-16.

[20] Jensen, Henrik. (2002). “Targeting Nominal Income Growth or Inflation?" American Economic Review, forthcoming.

[21] Kydland, Finn E., and Edward C. Prescott. (1990). "Business Cycles: Real Facts and a Monetary Myth," Federal Reserve Bank of Minneapolis, Quarterly Review, Spring, 3-18. 
[22] Lansing, Kevin J. (2000). "Exploring the Causes of the Great Inflation," Federal Reserve Bank of San Francisco, Economic Letter, 2000-21 (July 17).

[23] Lansing, Kevin J. (2002). "Real-Time Estimation of Trend Output and the Illusion of Interest Rate Smoothing," Federal Reserve Bank of San Francisco, Economic Review, pp. 17-34.

[24] Lansing, Kevin J. and Bharat Trehan (2001). "Forward-Looking Behavior and the Optimality of the Taylor Rule," Federal Reserve Bank of San Francisco, Working Paper 2001-03.

[25] Lucas, Robert E., Jr. (1976). "Econometric Policy Evaluation: A Critique," Carnegie-Rochester Conference Series on Public Policy, 1, 19-46..

[26] Mankiw. N. Gregory and Ricardo Reis. (2001). "Sticky Information Versus Sticky Prices: A Proposal to Replace the New Keynesian Phillips Curve," National Bureau of Economic Research, Working Paper 8290.

[27] McCallum, Bennett T. (1999). "Issues in the Design of Monetary Policy Rules," in J.B. Taylor and M. Woodford, eds., Handbook of Macroeconomics. Amsterdam: North Holland.

[28] McCallum, Bennett T. and Edward Nelson. (1999). "Nominal Income Targeting in an OpenEconomy Optimizing Model, Journal of Monetary Economics, 43, 553-578.

[29] Nelson, Edward and Kalin Nikolov. (2001). "A Real-Time Output Gap Series for the UK, 1965-2000: Construction, Analysis, and Implications for Inflation," Bank of England, Working Paper.

[30] Oliner, Stephen D. and Daniel E. Sichel. (2000). "The Resurgence of Growth in the Late 1990s: Is Information Technology the Story?" Journal of Economic Perspectives, 14, 3-22.

[31] Orphanides, Athanasios. (1999). "The Quest for Prosperity Without Inflation," Federal Reserve Board, unpublished manuscript.

[32] Orphanides, Athanasios. (2000). "Activist Stabilization Policy and Inflation: The Taylor Rule in the 1970s," Federal Reserve Board, Finance and Economics Discussion Ser ies Paper 2000-13.

[33] Orphanides, Athanasios and Simon van Norden (1999). "The Reliability of Output Gap Estimates in Real Time," Federal Reserve Board, Finance and Economics Discussion Series Paper 1999-38.

[34] Orphanides, Athanasios, Richard Porter, David Reifschneider, Robert Tetlow, and Frederico Finan. (2000). "Errors in the Measurment of the Output Gap and the Design of Monetary Policy," Journal of Economics and Business, 52, 117-141.

[35] Parry, Robert T. (2000). "Implications of Productivity Uncertainty for Monetary Policy," Business Economics, (January), 13-15.

[36] Perron, Pierre. (1989). "The Great Crash, The Oil Price Shock, and the Unit Root Hypothesis," Econometrica, 57, 1361-1401.

[37] Rudebusch, Glenn D. (2002). "Assessing Nominal Income Rules for Monetary Policy with Model and Data Uncertainty," Economic Journal, 112, 402-432.

[38] Sargent, Thomas J. (1999). The Conquest of American Inflation. Princeton: Princeton University Press.

[39] St-Amant, Pierre and Simon van Norden. (1997). "Measurement of the Output Gap: A Discussion of Recent Research at the Bank of Canada," Bank of Canada Technical Report No. 79 .

[40] Svensson, Lars E. O. and Michael Woodford. (2000). "Indicator Variables for Optimal Policy," National Bureau of Economic Research, Working Paper 7953.

[41] Taylor, John B. (1993). "Discretion versus Policy Rules in Practice," Carnegie-Rochester Conference Series on Public Policy, 39, 195-214.

[42] Taylor, John B. (1999). “A Historical Analysis of Monetary Policy Rules,” in J.B. Taylor, ed., Monetary Policy Rules, pp. 319-341. Chicago: University of Chicago Press. 
[43] Taylor, John B. (2000). "Comments on Athanasios Orphanides' The Quest for Prosperity Without Inflation," Presentation given at AEA Meetings in Boston MA, January 8, 2000.

[44] Weiland, Volker. (1998). "Monetary Policy and Uncertainty About the Natural Unemployment Rate," Federal Reserve Board, Finance and Economics Discussion Series Paper 1998-22.

[45] Woodford, Michael. (2001). "Inflation Stabilization and Welfare," National Bureau of Economic Research, Working Paper 8071. 
FIG 1: U.S. REAL GDP, 1947:1 to 2001:4

Segmented Linear Trend

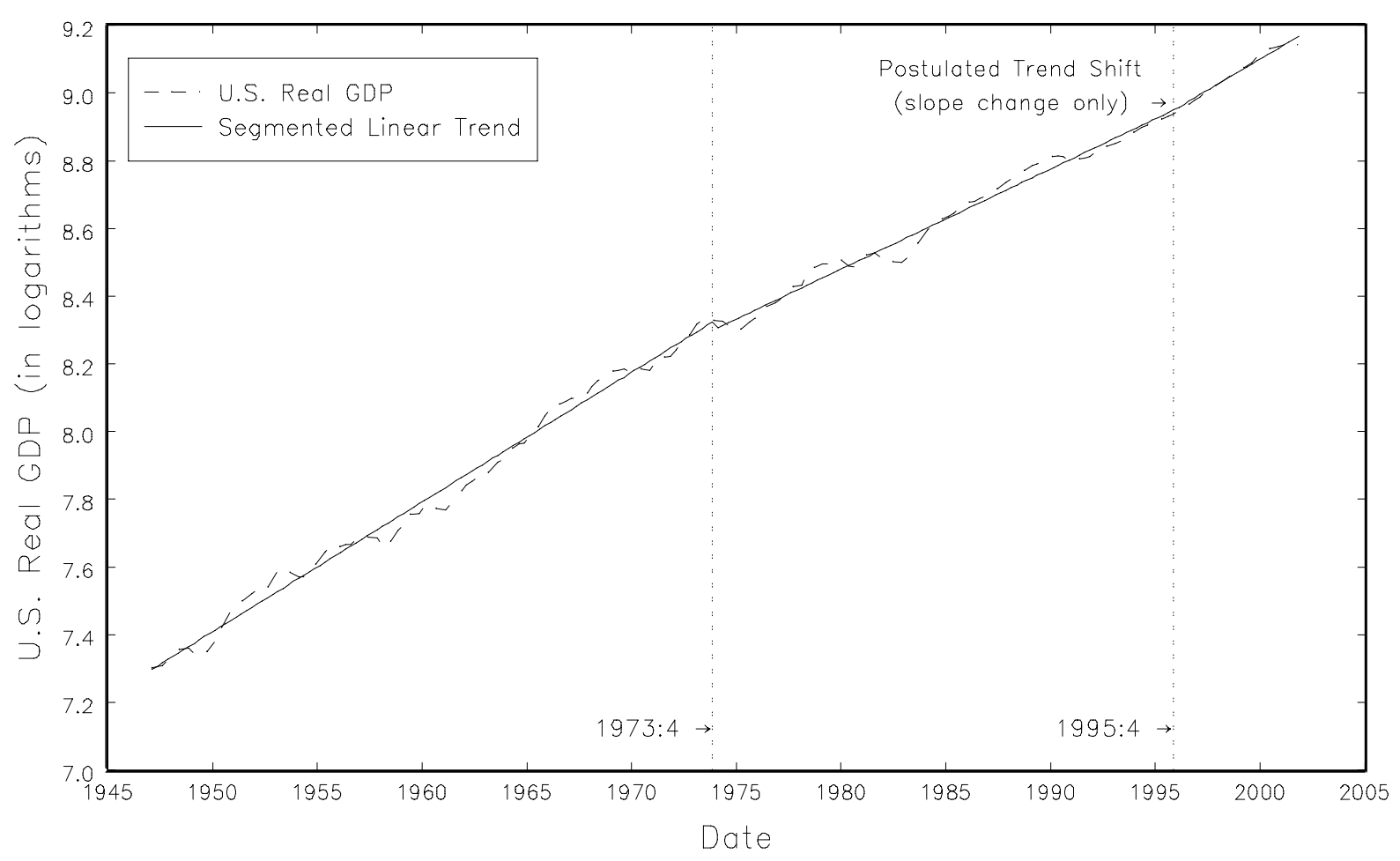


FIG 2a: U.S. INFLATION RATE, 1966:1 to 2001:4

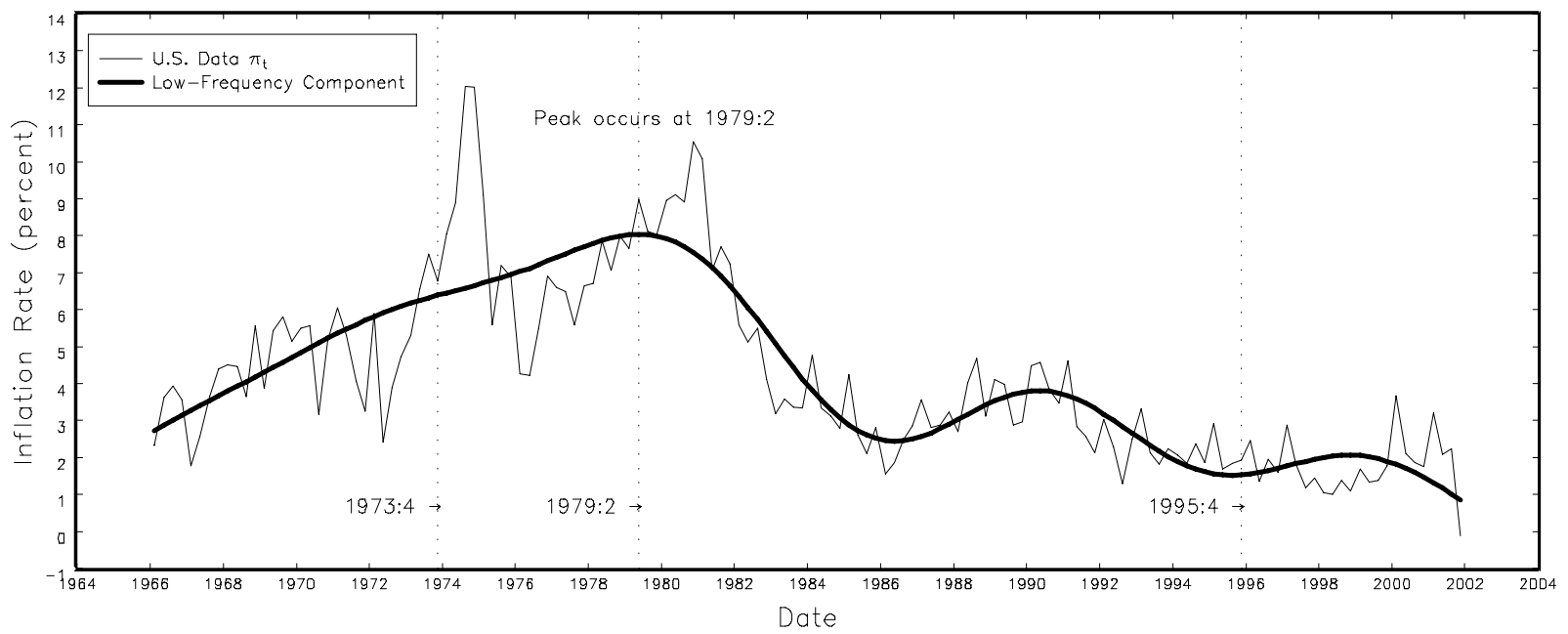

FIG 2b: U.S. REAL OUTPUT GAP, 1966:1 to 2001:4

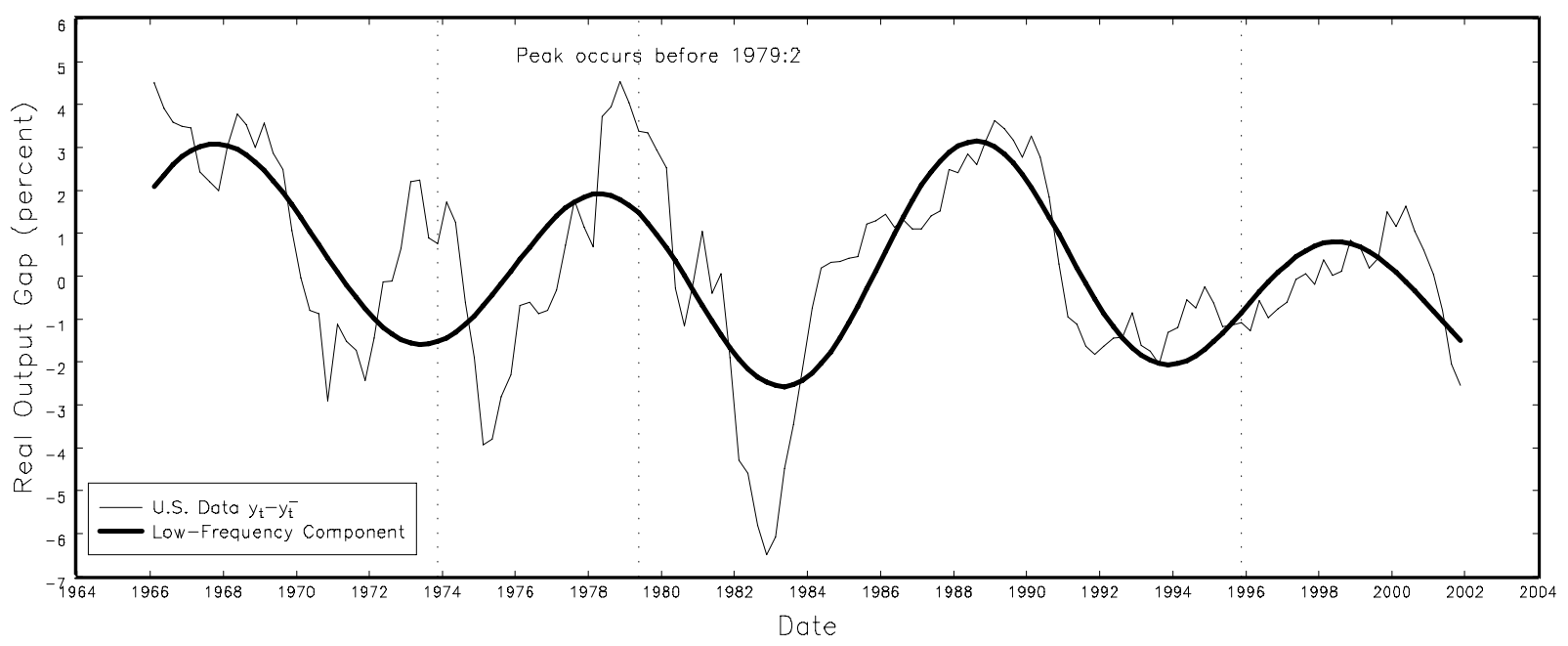

FIG 2c: U.S. FEDERAL FUNDS RATE, 1966:1 to 2001:4

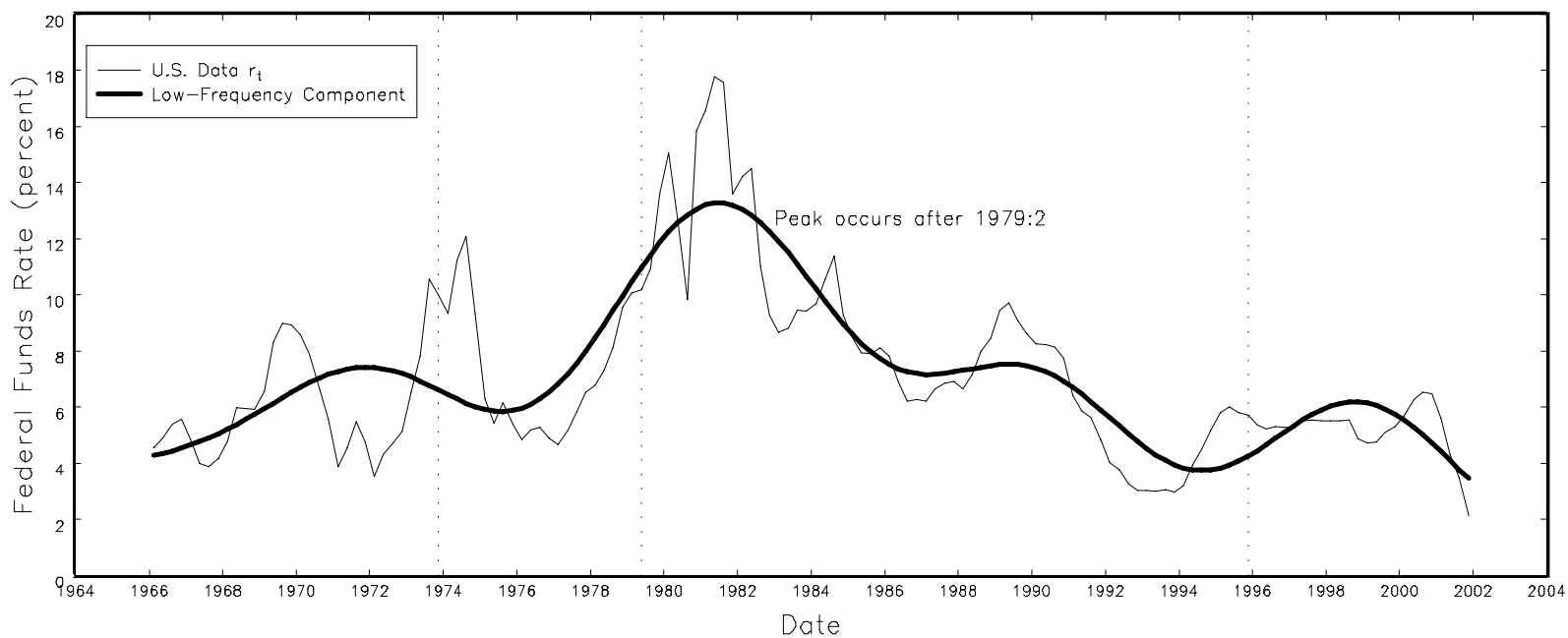


FIG 3a: U.S. FEDERAL FUNDS RATE VS TAYLOR-TYPE RULE

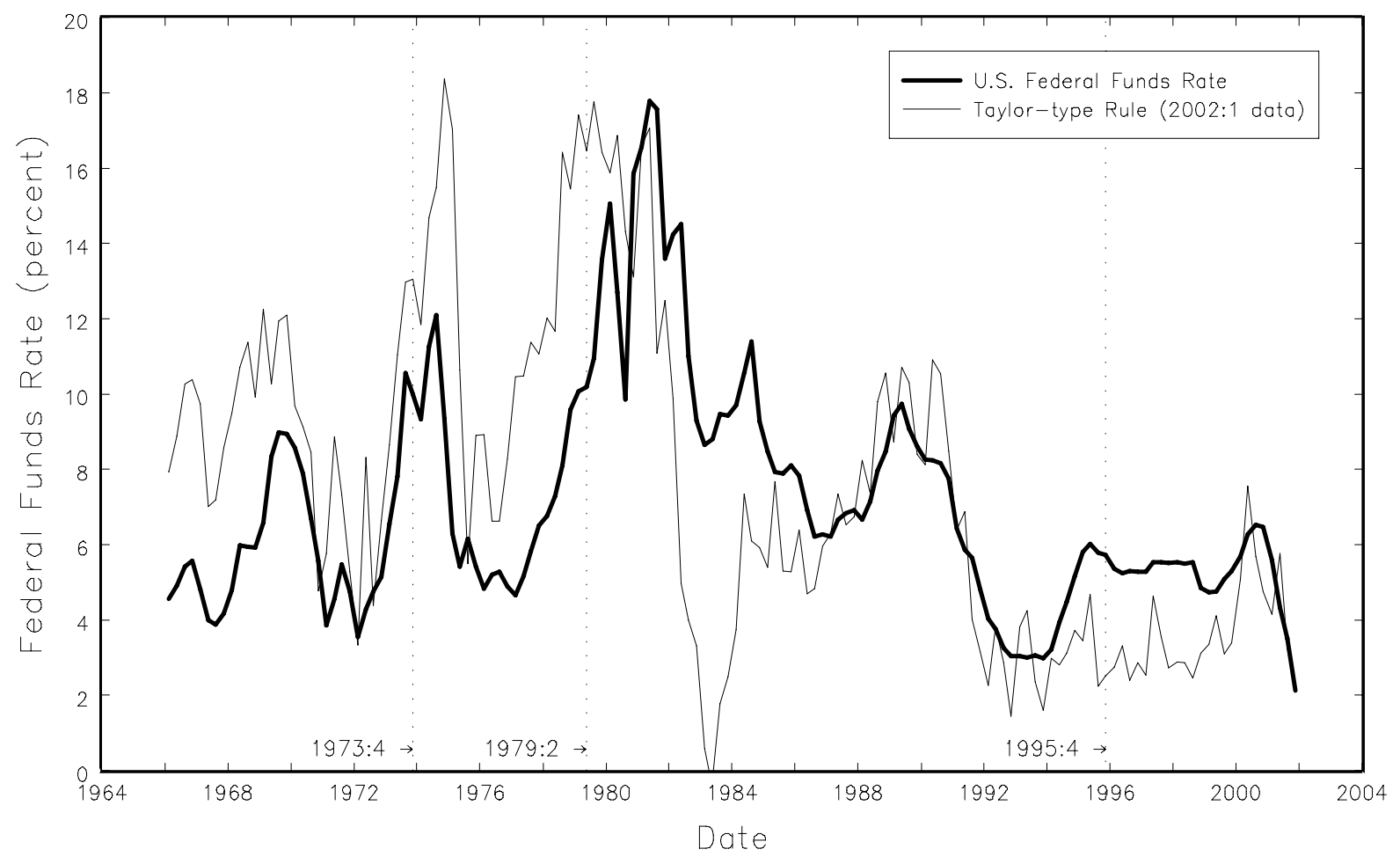

FIG 3b: U.S. FEDERAL FUNDS RATE VS NOMINAL INCOME GROWTH RULE

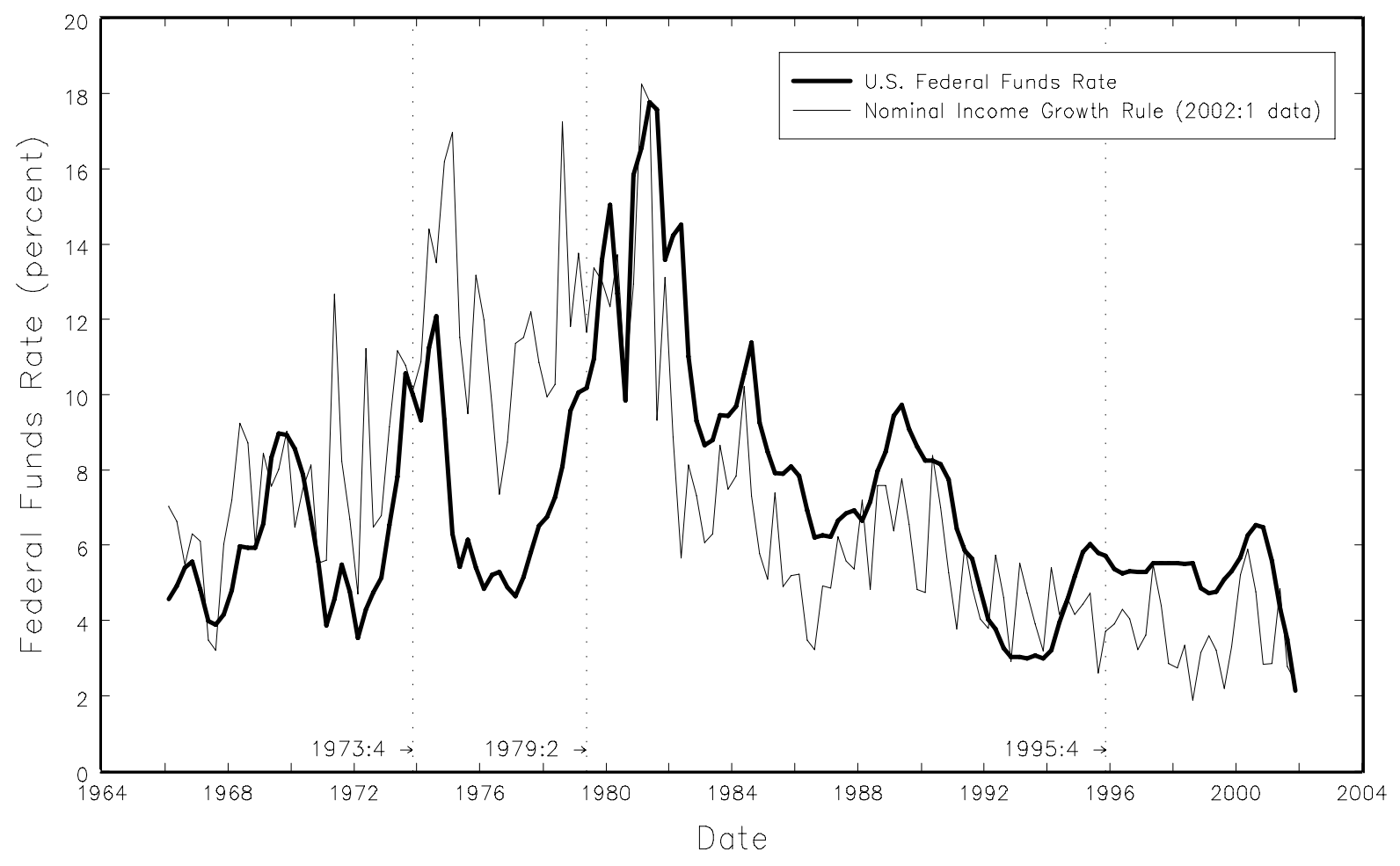


FIG 4a: POTENTIAL OUTPUT

Average Trajectory from 1000 Simulations

Taylor-type Rule, DLS Trend

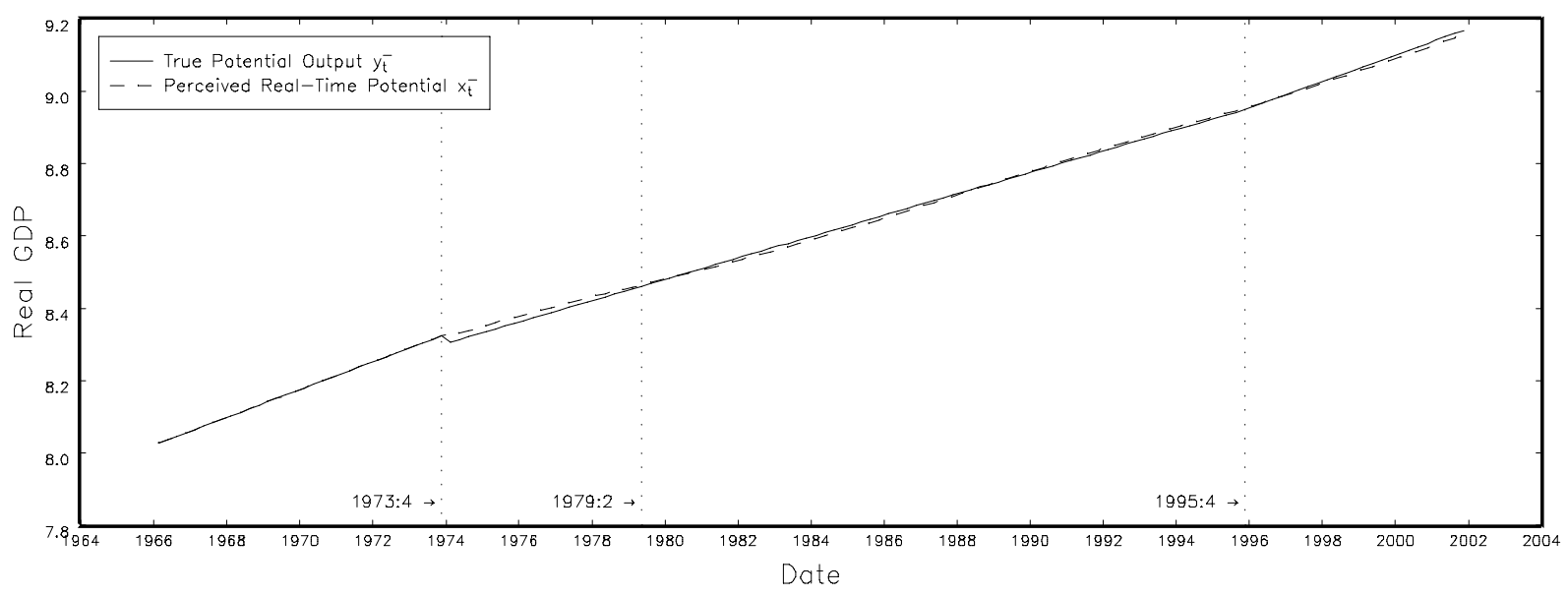

FIG 4b: OUTPUT GAP

Average Trajectory from 1000 Simulations

Taylor-type Rule, DLS Trend

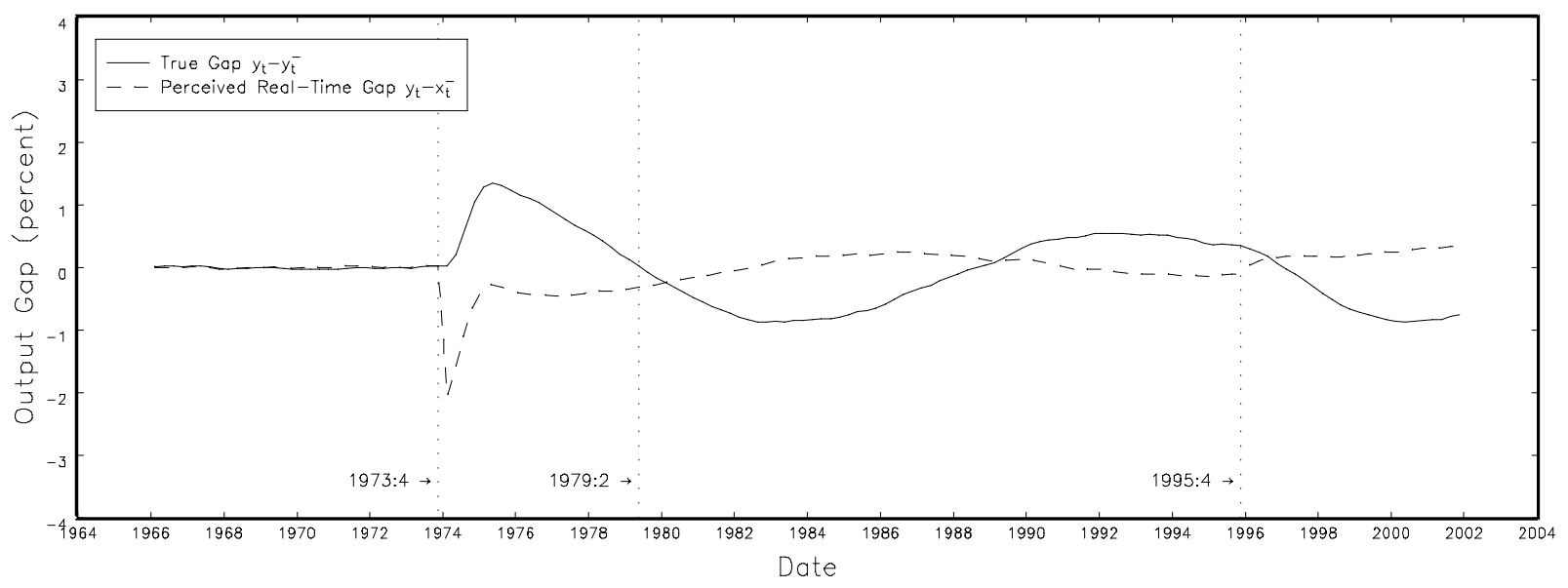

FIG 4c: FED'S PERCEIVED SHOCKS

Average Trajectory from 1000 Simulations

Taylor-type Rule, DLS Trend

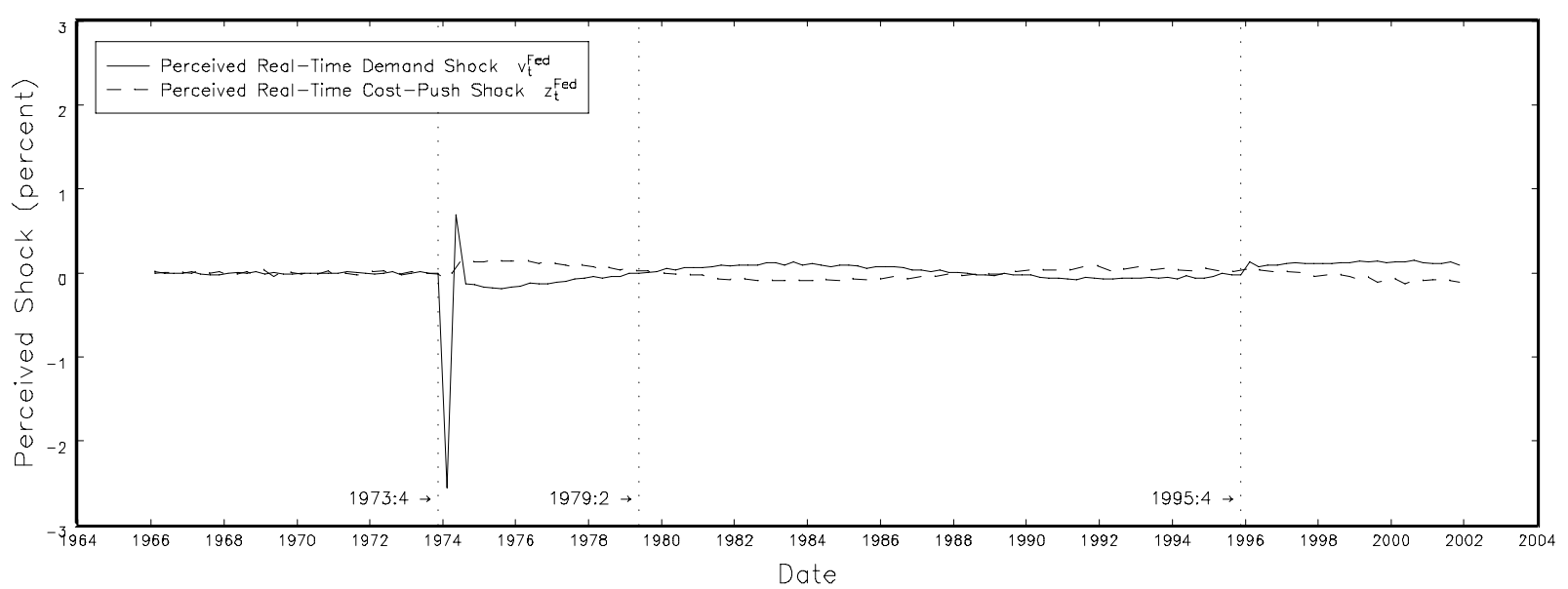


FIG 5a: POTENTIAL OUTPUT

Average Trajectory from 1000 Simulations

Nominal Income Growth Rule, DLS Trend

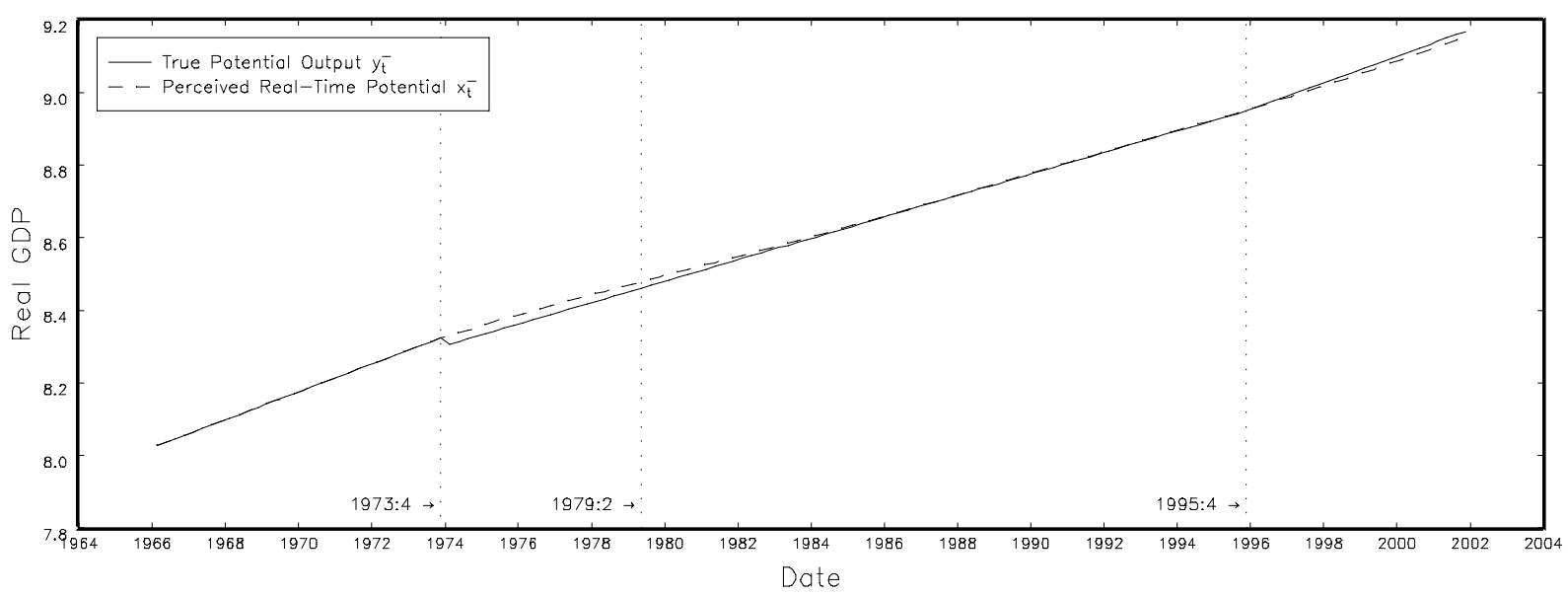

FIG 5b: OUTPUT GAP

Average Trajectory from 1000 Simulations

Nominal Income Growth Rule, DLS Trend

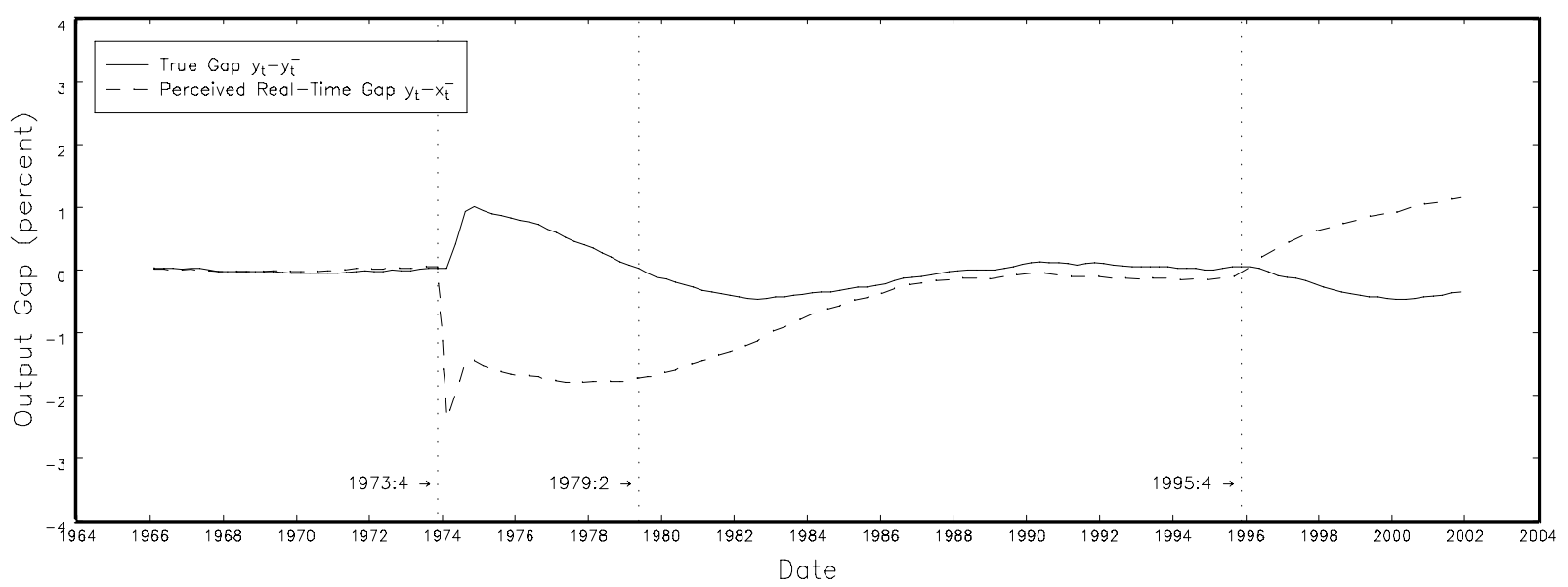

FIG 5c: FED'S PERCEIVED SHOCKS

Average Trajectory from 1000 Simulations

Nominal Income Growth Rule, DLS Trend

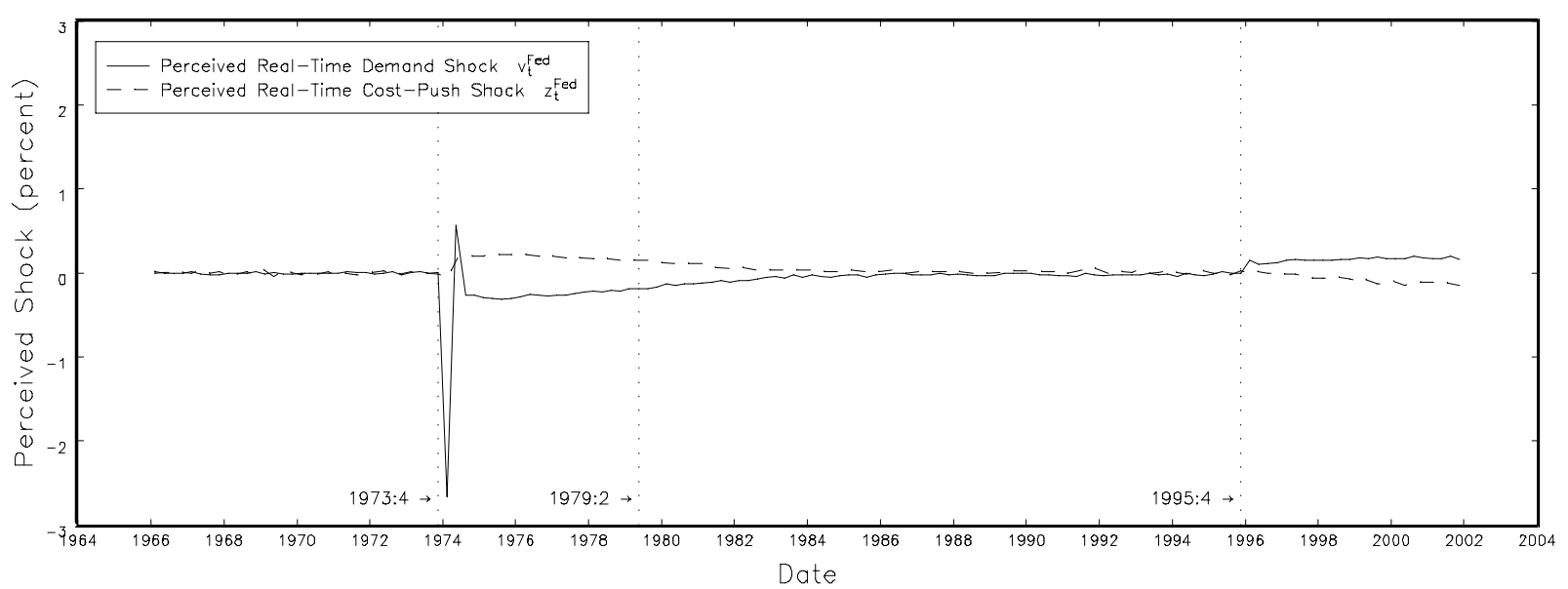


FIG 6a: INFLATION RATE

Average Trajectory from 1000 Simulations, DLS Trend

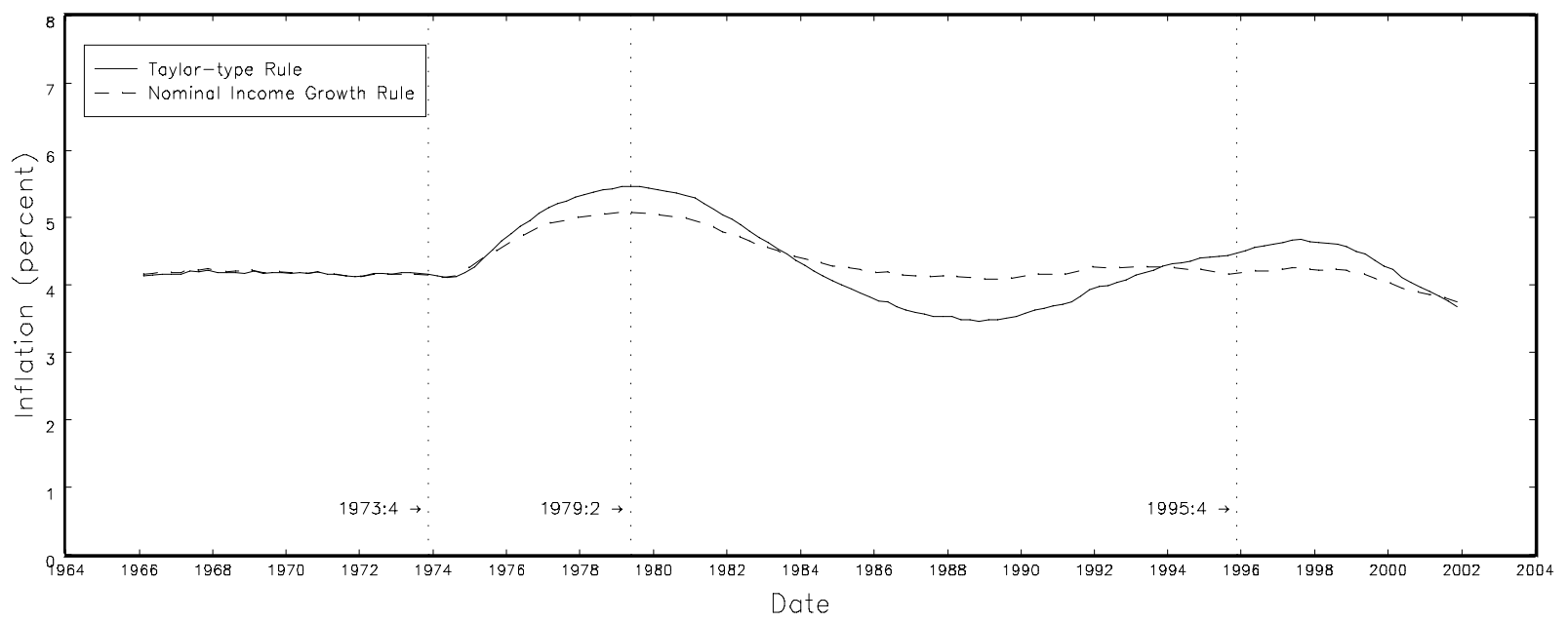

FIG 6b: OUTPUT GAP

Average Trajectory from 1000 Simulations, DLS Trend

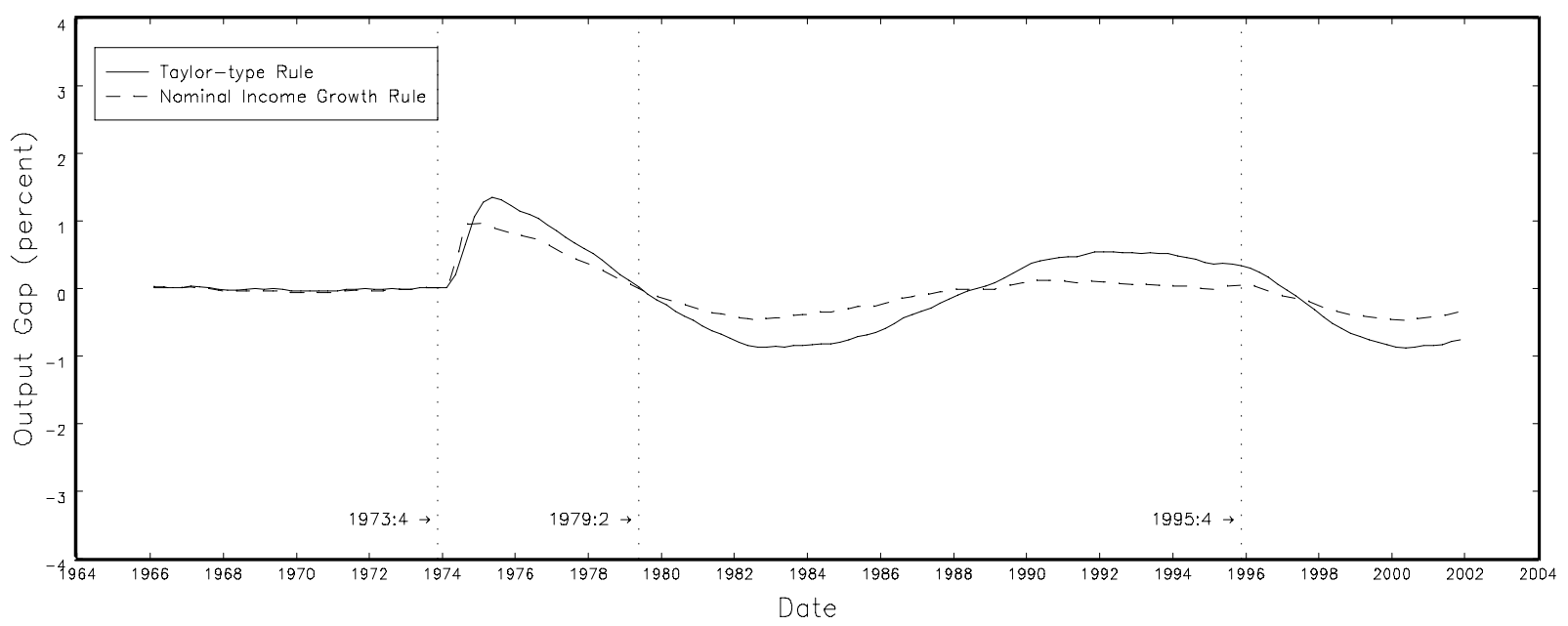

FIG 6c: ONE-PERIOD NOMINAL INTEREST RATE

Average Trajectory from 1000 Simulations, DLS Trend

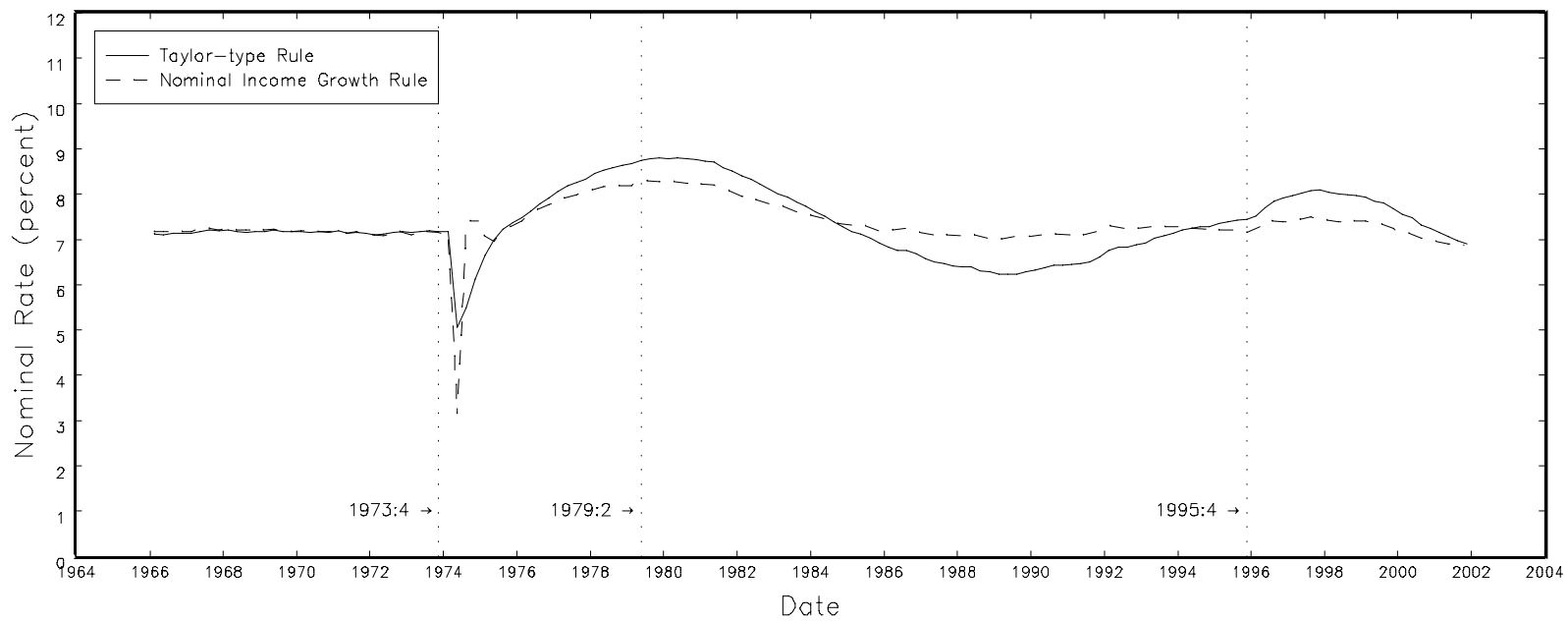


FIG 7: REAL-TIME ESTIMATE OF TREND GROWTH

Average Trajectory from 1000 Simulations

Taylor-type Rule, DLS Trend

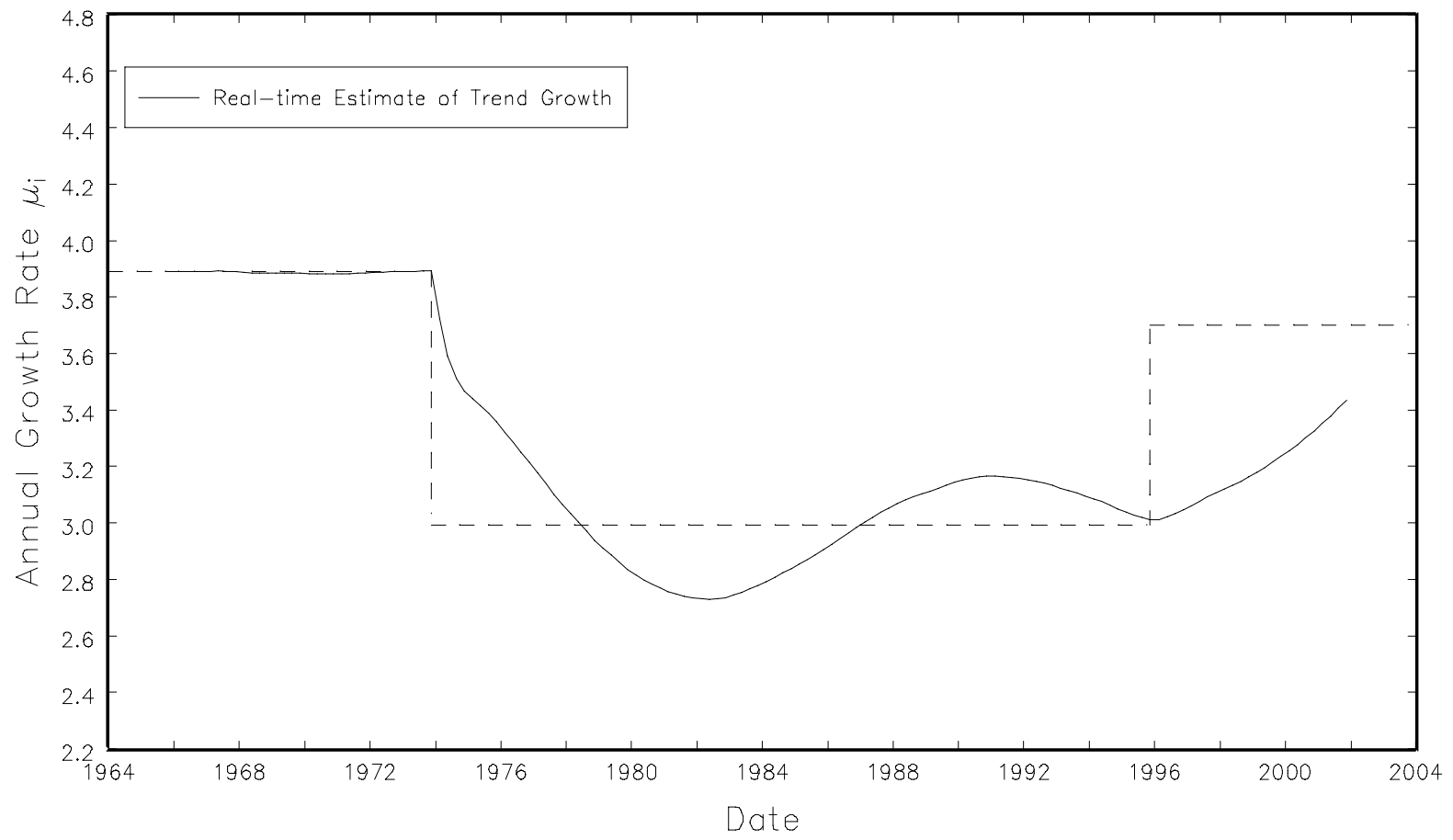

